Article

\title{
Exploring the Photodynamic Properties of Two Antiproliferative Benzodiazopyrrole Derivatives
}

\author{
Concetta Imperatore $1,+\left(\mathbb{D}\right.$, Mohammadhassan Valadan $2,+\left(\mathbb{D}\right.$, Luciana Tartaglione ${ }^{1,3}$, \\ Marco Persico ${ }^{1}$, Anna Ramunno ${ }^{4}$, Marialuisa Menna ${ }^{1}$ (), Marcello Casertano ${ }^{1}{ }^{1}$, \\ Carmela Dell'Aversano 1,3(1), Manjot Singh ${ }^{2}$, Maria Luisa d'Aulisio Garigliota ${ }^{4}$, \\ Francesco Bajardi ${ }^{2}$, Elena Morelli ${ }^{1}$, Caterina Fattorusso ${ }^{1, *} \mathbb{C}$, Carlo Altucci ${ }^{2, *}$ and \\ Michela Varra ${ }^{1, *}$ \\ 1 Department of Pharmacy, University of Naples Federico II, 80131 Naples, Italy; cimperat@unina.it (C.I.); \\ luciana.tartaglione@unina.it (L.T.); m.persico@unina.it (M.P.); mlmenna@unina.it (M.M.); \\ marcello.casertano@unina.it (M.C.); dellaver@unina.it (C.D.); emorelli@unina.it (E.M.) \\ 2 Department of Physics “Ettore Pancini”, University of Naples Federico II, 80126 Naples, Italy; \\ mohammadhassan.valadan@unina.it (M.V.); manjot.singh@unina.it (M.S.); francesco.bajardi@unina.it (F.B.) \\ 3 CoNISMa-Italian Interuniversity Consortium on Marine Sciences, Piazzale Flaminio 9, 00196 Rome, Italy \\ 4 Department of Pharmacy/DIFARMA, University of Salerno, 84084 Fisciano, Salerno, Italy; \\ aramunno@unisa.it (A.R.); mdaulisiogarigliota@unisa.it (M.L.d.G.) \\ * Correspondence: caterina.fattorusso@unina.it (C.F.); altucci@na.infn.it (C.A.); varra@unina.it (M.V.); \\ Tel.: +39-081-678544 (C.F.); +39-081-676293 (C.A.); +39-081-678540 (M.V.) \\ + These authors contributed equally to this work.
}

Received: 13 December 2019; Accepted: 11 February 2020; Published: 13 February 2020

\begin{abstract}
The identification of molecules whose biological activity can be properly modulated by light is a promising therapeutic approach aimed to improve drug selectivity and efficacy on the molecular target and to limit the side effects compared to traditional drugs. Recently, two photo-switchable diastereomeric benzodiazopyrrole derivatives 1RR and 1RS have been reported as microtubules targeting agents (MTAs) on human colorectal carcinoma p53 null cell line (HCT 116 p53-/-). Their $\mathrm{IC}_{50}$ was enhanced upon Light Emitting Diode (LED) irradiation at $435 \mathrm{~nm}$ and was related to their cis form. Here we have investigated the photo-responsive behavior of the acid derivatives of $\mathbf{1 R R}$ and 1RS, namely, $d \mathbf{1 R R}$ and $d \mathbf{1 R S}$, in phosphate buffer solutions at different $\mathrm{pH}$. The comparison of the UV spectra, acquired before and after LED irradiation, indicated that the trans $\rightarrow$ cis conversion of $d \mathbf{1 R R}$ and $d \mathbf{1 R S}$ is affected by the degree of ionization. The apparent rate constants were calculated from the kinetic data by means of fast UV spectroscopy and the conformers of the putative ionic species present in solution ( $\mathrm{pH}$ range: 5.7-8.0) were modelled. Taken together, our experimental and theoretical results suggest that the photo-conversions of trans $d \mathbf{1 R R} / d \mathbf{1 R S}$ into the corresponding cis forms and the thermal decay of cis $d \mathbf{1 R R} / d \mathbf{1 R S}$ are dependent on the presence of diazonium form of $d \mathbf{1 R R} / d \mathbf{1 R S}$. Finally, a photo-reaction was detected only for $d \mathbf{1 R R}$ after prolonged LED irradiation in acidic medium, and the resulting product was characterized by means of Liquid Chromatography coupled to High resolution Mass Spectrometry (LC-HRMS) and Nuclear Magnetic Resonance (NMR) spectroscopy.
\end{abstract}

Keywords: photoswitchable azoheteroarene; diazo derivative; cis-trans conversion; fast UV spectroscopy; LC-HRMS; conformational analysis; DFT optimization

\section{Introduction}

Photo-switchable molecules have gained increasing attention in recent years, as they can provide, by means of light irradiation having a proper wavelength, external spatio-temporal control of specific events $[1,2]$. This important feature makes photo-switchable molecules potentially useful in a 
wide-range of applications ranging from molecular electronics [3-5] to pharmacology [6-8], and molecular model for visualizing interactions between biomolecules [9-12]. Azobenzenes are the most studied class of photo-switchable molecules, in view of their ability to undergo, under appropriate irradiation, a quantitative and reversible trans-cis isomerization $[3,13]$. Furthermore, depending on the intended use, azobenzenes can be easily functionalized with different chemical groups enabling a fine modulation of their photochromic responses [3,13-16]. More recently, azoheteroarenes, in which one or both the benzene rings of the azobenzene structure are replaced with one or two hetero-aromatic five-membered ring(s) have shown interesting photo-responsive properties [17-19].

In this context, we have recently described the synthesis of some benzodiazopyrrole derivatives with photo-responsive antiproliferative activity against HCT 116 p53-/- cancer cells (Figure 1) [20]. In particular, results of the 3-(4,5-dimethylthiazol-2-yl)-2,5-diphenyltetrazolium bromide (MTT) test performed on this cancer cell line treated with the synthesized molecules and kept in the dark or under irradiation with pulsed LED at $435 \mathrm{~nm}$, showed that the occurrence of the trans-cis isomerization is correlated with the degree of cell growth inhibition [20]. The obtained data suggested that the cis isomers showed the greatest antiproliferative activities. Two of these molecules forming the diastereomeric mixture named 1a (Figure 1), exhibited the most interesting biological properties. Indeed, under irradiation, the inhibition of HCT 116 p53-/- cell growth treated with 1a was greater than those treated with its pure components, 1RR or 1RS, thus, suggesting that the biological activity of 1a could be associated with different mechanisms of action from those induced by $\mathbf{1 R R}$ and 1RS [20]. In addition, an in vitro tubulin polymerization test also evidenced that, under LED irradiation, the two stereomers differently inhibited the tubulin aggregation into microtubules [20].

With the aim to acquire more detailed information on the physico-chemical properties that can confer to 1a its specific biological properties, and considering that the tumor aggressiveness is correlated with the lowering of the $\mathrm{pH}$ around the membrane of cancer cells [21-24], we have performed more in depth investigations on the photo-responsive behavior of $d \mathbf{1 R R}$ and $d \mathbf{1 R S}$ (the free carboxylic acids of 1RR and 1RS, Figure 1) in the $\mathrm{pH}$ range 8.0-5.7. To this purpose, we carried out UV and fast UV spectroscopy, and computational analyses. Furthermore, we have also explored the photo-transformation of $d \mathbf{1 R R}$ in acidic condition under prolonged LED irradiation using Liquid Chromatography High Resolution Mass Spectrometry (LC-HRMS), 1D and 2D NMR and UV techniques.

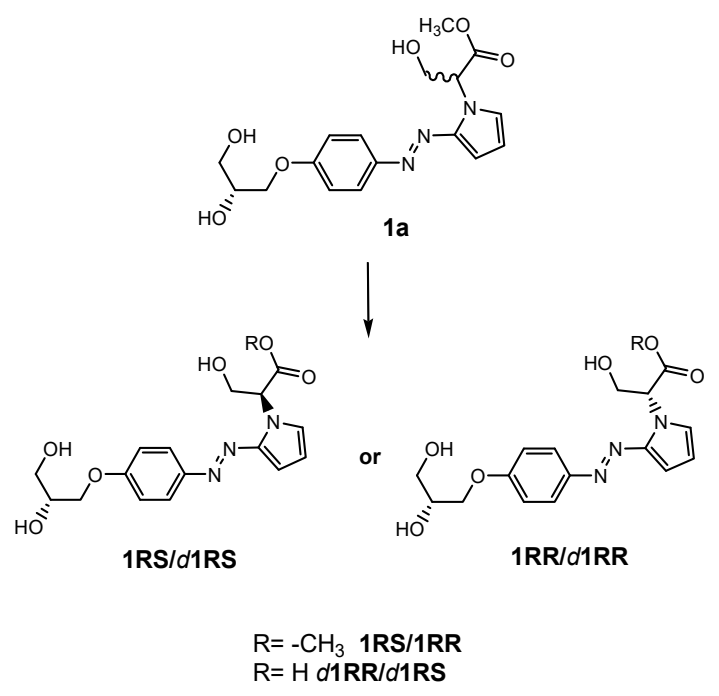

Figure 1. The benzodiazopyrrole derivatives previously described (the diastereomeric mixture and its pure stereomers $1 \mathbf{R R}$ and $\mathbf{1 R S}$ ) that have shown photo-responsive antiproliferative activity against HCT 116 p53-/- cancer cells [20], and the water soluble deprotected $d \mathbf{1 R R}$ and $d \mathbf{1 R S}$ herein explored for their photo-responsive properties. 


\section{Results and Discussion}

\subsection{The Behavior of Trans/Cis Isomers of d1RR/d1RS in Differently Buffered Water-Based Solutions}

In order to characterize the photo-responsive properties of $d \mathbf{1 R R} / d \mathbf{1 R S}$ in phosphate buffered solutions, the UV spectra of the two stereomers at different $\mathrm{pH}(8.0,7.5,7.0,6.7,6.5,5.7)$ were acquired, in the dark and under LED irradiation at $435 \mathrm{~nm}$. In the dark, the UV spectra of $d \mathbf{1 R R} / d \mathbf{1 R S}$ showed two main, partially overlapped, UV bands centred at 394 and $424 \mathrm{~nm}$ (Figure 2A and Figure S1A). At $\mathrm{pH}=8.0$ and 7.0, after the irradiation of the samples, the UV profiles underwent some changes. At $\mathrm{pH}=8.0$ (Figure 2B and Figure S1B) the comparison of the two UV spectra, acquired before and after the irradiation, mostly showed a strong decreasing in the intensity of the UV bands at 394 and $424 \mathrm{~nm}$ and the appearance of a new band centred at $343 \mathrm{~nm}$. This band, in the corresponding methyl ester derivatives 1RR/1RS, has been attributed to the presence of the cis stereomer [20], which, according to the literature, was responsible for the differences of the light absorption before and after irradiation, due to the non-planar configuration of cis stereomers [13-19]. At $\mathrm{pH}=7.0$ only a slight decrease of the two main bands was observed in the UV spectra before and after the irradiation. A similar, but not equivalent behavior was observed for 1RR/1RS in water-based solutions at $\mathrm{pH}$ 7.0. Indeed, in the case of $d \mathbf{1 R R}$ and $d \mathbf{1 R S}$, the relative intensity between the band at $340 \mathrm{~nm}$ (cis isomer) and those centred around $400 \mathrm{~nm}$ (trans isomer) was significantly reduced with respect to that previously observed for 1RR/1RS, possibly because an increasing of the rate of the cis $\rightarrow$ trans isomerization caused a change of the relative ratio between the concentration of the cis/trans isomers, because other species are present in solution, or both. Furthermore, this phenomenon was emphasized by increasing the $\mathrm{pH}$ of the buffered solution. Indeed, at $\mathrm{pH}<7.0$, there was no change in the UV band (Figure 2C,D and Figure S1C,D). Despite this, the cis $\rightarrow$ trans isomerization could still happen at this $\mathrm{pH}$ value, although it could not be monitored with normal UV spectroscopy.
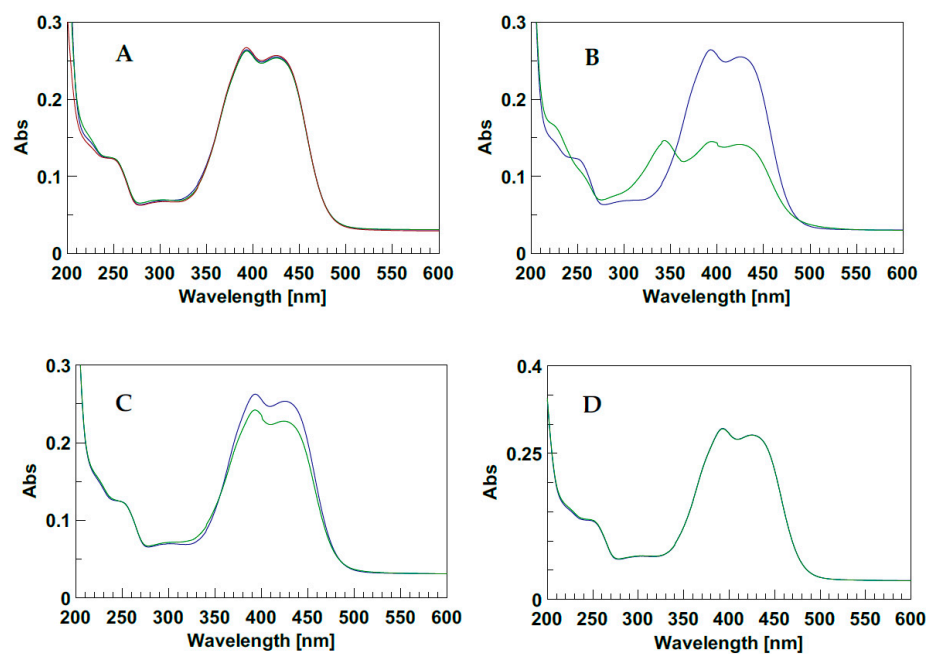

Figure 2. (A) UV spectra of $d 1 \mathrm{RR}$ in the dark at different $\mathrm{pH}$ : $\mathrm{Red} \mathrm{pH}=5.7$; blue $\mathrm{pH}=7.0$; green $\mathrm{pH}=8.0$. (B-D) UV spectra before (blue line) and after (green line) irradiation with LED at $435 \mathrm{~nm}(1$ $\min , 1 \mathrm{LED})$, at $\mathrm{pH}=8.0,7.0$, and 5.7, respectively.

To better explore this phenomenon, we monitored the trans $\rightarrow$ cis conversion of $d \mathbf{1 R R} / d \mathbf{1} \mathbf{R S}$ under laser irradiation at $435 \mathrm{~nm}$ and the cis $\rightarrow$ trans thermal decay in the dark in buffered solutions $(20 \mathrm{mM}$ of phosphate buffer solutions at $\mathrm{pH}$ values of 5.7, 6.5, 6.7, 7.0, 7.5 and 8.0) by means of fast UV spectroscopy (a picture of this experimental set-up of the instrument is reported in Figure S2). The acquisition of time-dependent absorption spectra in the $220-430 \mathrm{~nm}$ range gave rise to the $2 \mathrm{D}$ graphical representation of time-dependent changes in absorption bands (Figure 3A,B and Figure S3A,B). Data coming from each set of measurements were processed at two wavelengths, 340 and $400 \mathrm{~nm}$ (Figure 3C,D and Figure S3C,D), from which the apparent rate constants for $d \mathbf{1 R R} / d \mathbf{1 R S}$ trans $\rightarrow$ cis photo-conversions 
and those for the corresponding thermal relaxations were calculated (Table 1). As an example, the analysis of $d \mathbf{1 R R}$ trans $\rightarrow$ cis photo-conversion at $\mathrm{pH}=8.0$, and of the corresponding thermal decay in

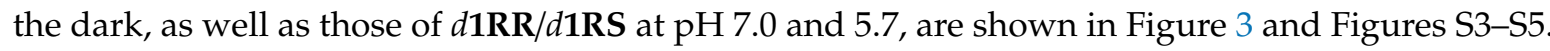
Under irradiation at $435 \mathrm{~nm}$, a time-dependent decrease of the UV band around $400 \mathrm{~nm}$ (trans isomer) and an increase of that around $340 \mathrm{~nm}$ (cis isomer) occurred (Figure 3). As above mentioned, this observation should account for a trans-to-cis photo-isomerization. Conversely, turning off the laser irradiation, caused a time-dependent increase of the UV band at $400 \mathrm{~nm}$ (trans isomer) and a decrease of that at $\approx 340 \mathrm{~nm}$ (cis isomer) (Figure S3), due to the cis thermal decay. Noteworthy, the data reported in the Figures S4 and S5, showing the changes in the absorption bands centered at 340 and $400 \mathrm{~nm}$ for both $d \mathbf{1 R R / d 1 R S}$ under laser irradiation and in the dark (i.e., with laser off), suggest that the cis-trans isomerizations always occurred at the lower $\mathrm{pH}$ value.
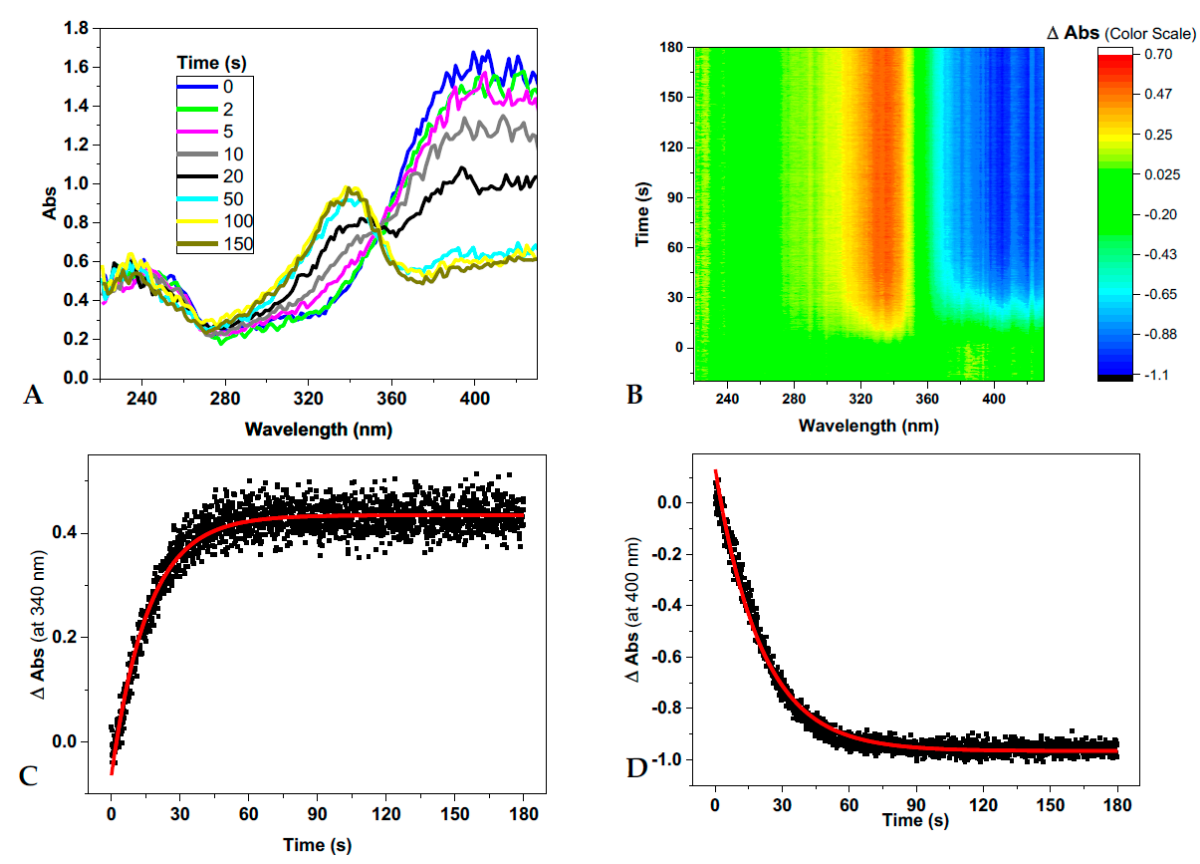

Figure 3. (A-D) d1RR trans to cis conversion ( $\mathrm{pH}=8.0$ ) under $5 \mathrm{~mW}$ laser irradiation at $435 \mathrm{~nm}$. (A) Time-dependent absorption spectra of $d \mathbf{1 R R}$. (B) 2D graphical representation of the changes of absorbance of $d \mathbf{1 R R}$ plotted as a function of time. (C,D) The changes of absorbance at specific wavelengths, 340 and $400 \mathrm{~nm}$, together with their best fit (red solid lines). Reaction half-lives and apparent rate constants are deduced on these fittings.

Table 1. Apparent rate constants calculated in $\mathrm{s}^{-1}$ from kinetic data by means of fast UV spectroscopy. The reported values have about $10 \%$ uncertainty.

\begin{tabular}{|c|c|c|c|c|c|c|c|c|}
\hline \multirow{3}{*}{$\mathrm{pH}$} & \multicolumn{4}{|c|}{$1 R R$} & \multicolumn{4}{|c|}{$1 R S$} \\
\hline & \multicolumn{2}{|c|}{$\begin{array}{c}\text { trans } \rightarrow \text { cis } \\
h v\end{array}$} & \multicolumn{2}{|c|}{$\begin{array}{c}\text { cis } \rightarrow \text { trans } \\
\Delta\end{array}$} & \multicolumn{2}{|c|}{$\begin{array}{c}\text { trans } \rightarrow \text { cis } \\
h v\end{array}$} & \multicolumn{2}{|c|}{$\begin{array}{c}\text { cis } \rightarrow \text { trans } \\
\Delta\end{array}$} \\
\hline & $340 \mathrm{~nm}$ & $400 \mathrm{~nm}$ & $340 \mathrm{~nm}$ & $400 \mathrm{~nm}$ & $340 \mathrm{~nm}$ & $400 \mathrm{~nm}$ & $340 \mathrm{~nm}$ & $400 \mathrm{~nm}$ \\
\hline 8.0 & $6.30 \times 10^{-2}$ & $4.95 \times 10^{-2}$ & $4.18 \times 10^{-3}$ & $6.19 \times 10^{-3}$ & $6.86 \times 10^{-2}$ & $5.64 \times 10^{-2}$ & $3.69 \times 10^{-3}$ & $5.10 \times 10^{-3}$ \\
\hline 7.5 & $6.54 \times 10^{-2}$ & $5.21 \times 10^{-2}$ & $6.08 \times 10^{-3}$ & $1.03 \times 10^{-2}$ & $7.38 \times 10^{-2}$ & $5.97 \times 10^{-2}$ & $6.66 \times 10^{-3}$ & $9.22 \times 10^{-3}$ \\
\hline 7.0 & $8.35 \times 10^{-2}$ & $7.30 \times 10^{-2}$ & $1.57 \times 10^{-2}$ & $1.93 \times 10^{-2}$ & $7.79 \times 10^{-2}$ & $6.48 \times 10^{-2}$ & $1.48 \times 10^{-2}$ & $2.10 \times 10^{-2}$ \\
\hline 6.7 & $9.00 \times 10^{-2}$ & $7.22 \times 10^{-2}$ & $3.65 \times 10^{-2}$ & $5.77 \times 10^{-2}$ & $9.50 \times 10^{-2}$ & $7.70 \times 10^{-2}$ & $3.85 \times 10^{-2}$ & $5.33 \times 10^{-2}$ \\
\hline 6.5 & 0.100 & $8.06 \times 10^{-2}$ & $4.95 \times 10^{-2}$ & $6.30 \times 10^{-2}$ & $9.00 \times 10^{-2}$ & $7.96 \times 10^{-2}$ & $4.95 \times 10^{-2}$ & $6.03 \times 10^{-2}$ \\
\hline 6.0 & 0.187 & $8.89 \times 10^{-2}$ & 0.148 & 0.239 & 0.116 & 0.210 & 0.131 & 0.148 \\
\hline 5.7 & 0.224 & 0.277 & 0.578 & 0.169 & 0.224 & 0.385 & 0.210 & 0.347 \\
\hline
\end{tabular}


All the calculated values of the apparent rate constants increase by decreasing the $\mathrm{pH}$ of the solutions, or also decreases by increasing the concentration of $\mathrm{OH}^{-}$ions (Table 1 and Figures 3 and 4). These trends showed that the trans $\leftrightarrow$ cis $d \mathbf{1 R R} / d \mathbf{1 R S}$ conversions exhibited the general effects of acidic catalysis, suggesting that, in water-based solutions, both the isomerizations could be affected by the acid-base ionizations [25-29].
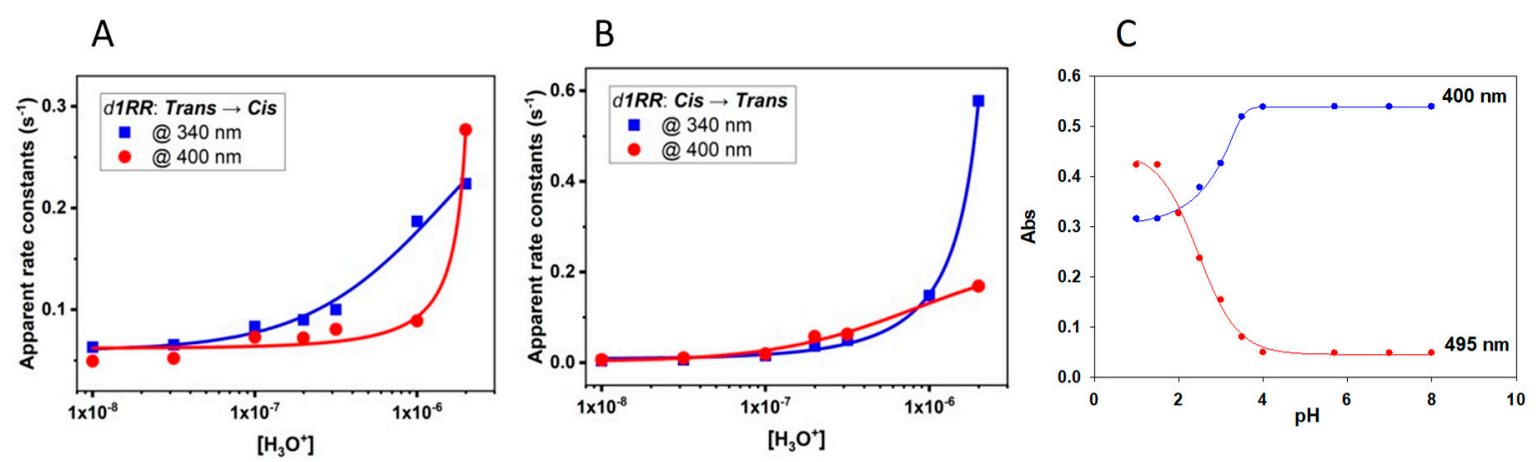

Figure 4. Changes in the apparent rate constants versus $\mathrm{pH}$ in the 5.7-8.0 range. (A) $d \mathbf{1} \mathbf{R} \mathbf{R}$ trans $\rightarrow$ cis (irradiated at $435 \mathrm{~nm}$ ). (B) $d \mathbf{1} \mathbf{R} \mathbf{R}$ cis $\rightarrow$ trans (thermal decay). Both the transitions were monitored at 400 $\mathrm{nm}$ (circle) and $340 \mathrm{~nm}$ (square). Data coming from interpolations of the data are reported in Table S1. (C) Titration curve of $d \mathbf{1 R R}$ in phosphate buffered solution obtained plotting the absorptions at 400 and $495 \mathrm{~nm}$ versus $\mathrm{pH}$.

At least in principle, we can consider that at very low $\mathrm{pH}$ both trans/cis isomers of $d \mathbf{1 R R} / d \mathbf{1 R S}$ exist only in the corresponding protonated species provoking the highest possible rate for the trans $\leftrightarrow$ cis conversion. In contrast, in alkaline condition, the concentration of the totally unprotonated species reaches its maximum value making lowest the rate of the trans $\leftrightarrow$ cis conversions. Around the $\mathrm{pH}$ corresponding to the $\mathrm{pKa}$ value of the diazonium ions, the protonated and unprotonated species of $d \mathbf{1 R R} / d \mathbf{1 R S}$ trans/cis isomers should coexist in the solution, and the apparent rate constant of the trans $\leftrightarrow$ cis isomerization strongly depends on the relative abundance of the two species. Accordingly, a small variation of $\mathrm{pH}$ in the range containing the $\mathrm{pKa}$, inducing an inversion in the relative abundance of protonated and unprotonated species, should allow a strong variation of the trans $\leftrightarrow$ cis conversion rates [25-29]. Thus, plots of the apparent rate constants versus $\mathrm{pH}$ should give titration curves, from which the pKa of the diazo group in each species could be obtained. However, our data gave rise to only partial titration curves (Figure 4A,B and Figure S6A,B) since, we explored the $\mathrm{pH} / \mathrm{rate}$ combinations around the physiological $\mathrm{pH}$ value. Despite this, the data reported in Table 1 were plotted and tentatively interpolated (Figure 4 and Figure S6) according to the method developed by Dunn et al. [27] to analyze the trans $\rightarrow$ cis isomerization of diazobenzenes in acidic medium. From the parameters of the corresponding curves (Table S1) pKa values in the range of 5.1-6.0 were obtained.

Interestingly, for both the two stereomers, $d \mathbf{1 R R} / d \mathbf{1 R S}$, the two trends of the apparent rate constants calculated from the measurements performed at 400 (a band of the trans isomers) and $340 \mathrm{~nm}$ (a band of the cis stereomers), as well as the trend of each absorption band measured under irradiation or during the thermal decay showed some differences (Figure 4 and Figure S6), possibly because of the

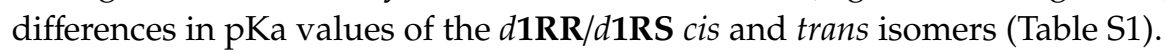

At lower $\mathrm{pHs}$, the trend of the apparent rate constants, obtained from the measures performed at 400 and $340 \mathrm{~nm}$, were also reversed comparing the two stereomers $d \mathbf{1 R R}$ (Figure 4) and $d \mathbf{1 R S}$ (Figure S6). Indeed, for $d \mathbf{1 R S}$ at $\mathrm{pH}<6.5$, the apparent rate constants obtained at $400 \mathrm{~nm}$ increased faster than that measured at $340 \mathrm{~nm}$, and the opposite trend was observed for $d \mathbf{1 R R}$.

Accordingly, the measured absorptions at 340 and $400 \mathrm{~nm}$ at different $\mathrm{pH}$ should contain also the contribution of the UV bands of at least one specie, that is the zwitterionic form of $d \mathbf{1 R R} / d \mathbf{1 R S}$. (see the computational analyses below). The final amplitude of a specific absorption band should depend on 
the molar extinction coefficient and on the concentration of each species, cis, trans or the zwitterionic form, at a specific wavelength.

To further explore this issue, we performed further UV versus $\mathrm{pH}$ titrations on the aqueous samples of $d \mathbf{1 R R}$ and $d \mathbf{1 R S}$ buffered at $\mathrm{pH}=8.0$. At each $\mathrm{pH}$ variation, the $\mathrm{UV} / \mathrm{vis}$ spectra of the trans isomers were measured (Figure S7). The obtained data showed that an additional UV band centred at about $500 \mathrm{~nm}$ appeared in the UV spectra of both species at $\mathrm{pH}$ lower than 4.5. According to literature data [25-29], this absorption band should be related to the corresponding diazonium ions of $d \mathbf{1 R R} / d \mathbf{1 R S}$. Each titration curve obtained plotting the absorptions measured at 400 or $495 \mathrm{~nm}$ versus $\mathrm{pH}$ supported the presence of an inflection point attributable to a pKa around 2.0-2.5 for each specie (Figure $4 \mathrm{C}$ and Figure S6C).

Computational Studies

Computational studies were performed in order to model the ionic species (ground states) of the trans and cis isomers of $d \mathbf{1 R R}$ and $d \mathbf{1 R S}$ present in solution in the $\mathrm{pH}$ range of 5.7-8.0.

At first, the apparent pKa values of $d \mathbf{1 R R}$ and $d \mathbf{1 R S}$ were calculated (ACD/Percepta, Advanced Chemistry Development, Inc., Toronto, ON, Canada, 2017, http://www.acdlabs.com). Results are reported in Scheme 1. By using the obtained pKa values, the different ratios of $d \mathbf{1 R R} / d \mathbf{1 R S}$ ionic species present at the $\mathrm{pH}$ values considered in the UV experiments reported in Table 1, were calculated too (Table S2).

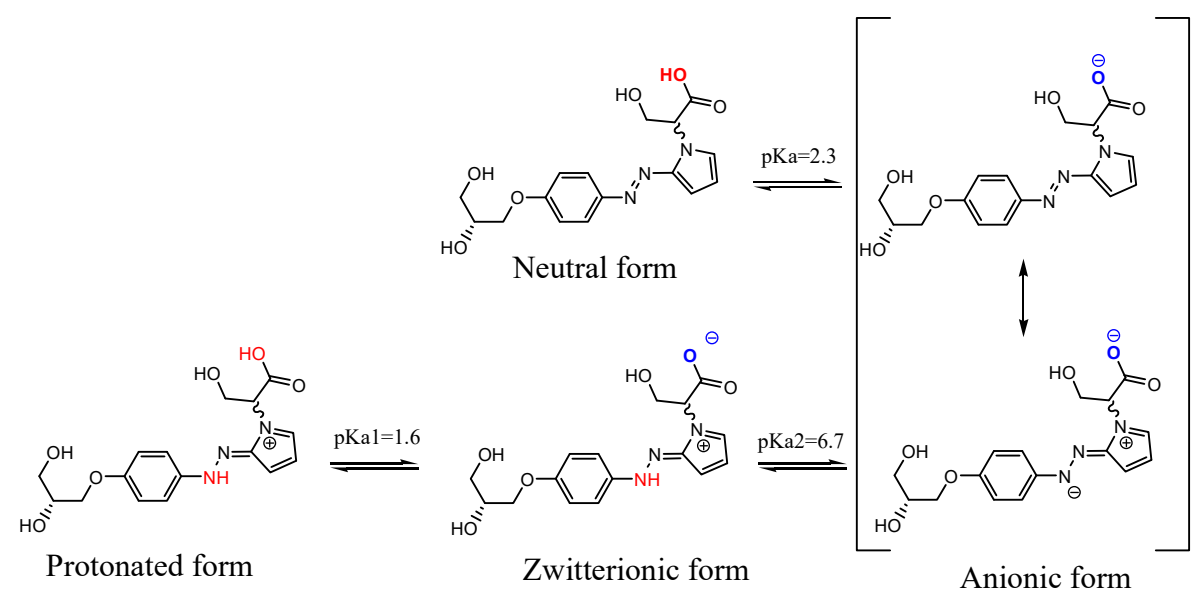

Scheme 1. Structures of ionic forms, and pka values calculated for $d \mathbf{1 R R} / d \mathbf{1 R S}$ using the ACD/Percepta software (ACD/Percepta, Advanced Chemistry Development, Inc., Toronto, ON, Canada, 2017, http: //www.acdlabs.com).

Then, the molecular models of the putative ionic species of $d \mathbf{1 R R}$ and $d \mathbf{1 R S}$ present in solution in the $\mathrm{pH}$ range 5.7-8.0 (i.e., the anionic forms of the trans and cis isomers and the zwitterionic form; Scheme 1; Table S2), were built and their conformational space was systematically sampled by means of molecular mechanics (MM) calculations (see the experimental section for details). The global minimum energy conformer (GM) for each species was identified, and all the other minima were ranked by their energy difference from the $\mathrm{GM}\left(\Delta \mathrm{E}_{\mathrm{GM}}\right)$. The conformers were grouped into conformational families according to the relative positioning of the phenyl- and pyrrole-substituted rings with respect to the diazo group (torsional angles $\tau 1$ and $\tau 2$ ), and further divided into sub-families according to the intramolecular interactions present within the structure (Tables S3-S8, Figures 5 and 6, Figures S8 and S9). It resulted that the conformers of the trans isomers always presented the $\mathrm{N}=\mathrm{N}$ bond and the two adjacent aromatic rings lying on the same plane (Figure 5, I-II; Figure S8, I-II; Tables S3 and S5). On the contrary, the conformers obtained for the cis isomers presented the phenyl- and the pyrrole-substituted rings never lying on the $\mathrm{N}=\mathrm{N}$ bond plane, mostly, including the $\mathrm{GM}$ (sub-family IVj), presenting a gauche (twisted) conformation with respect to the $\mathrm{N}=\mathrm{N}$ bond (Figure 5, III-V; Figure S8, III-V; Tables S4 
and S6). In some minima (sub-family $\mathrm{V}_{\mathrm{L}}$ ) the pyrrole ring is almost orthogonal with respect to the $\mathrm{N}=\mathrm{N}$ bond plane. In any case, the conformers of both the trans and the cis isomers are all characterized by the presence of an intramolecular H-bond involving a nitrogen atom of the diazo group and a hydrogen atom of the substituent on the pyrrole ring.
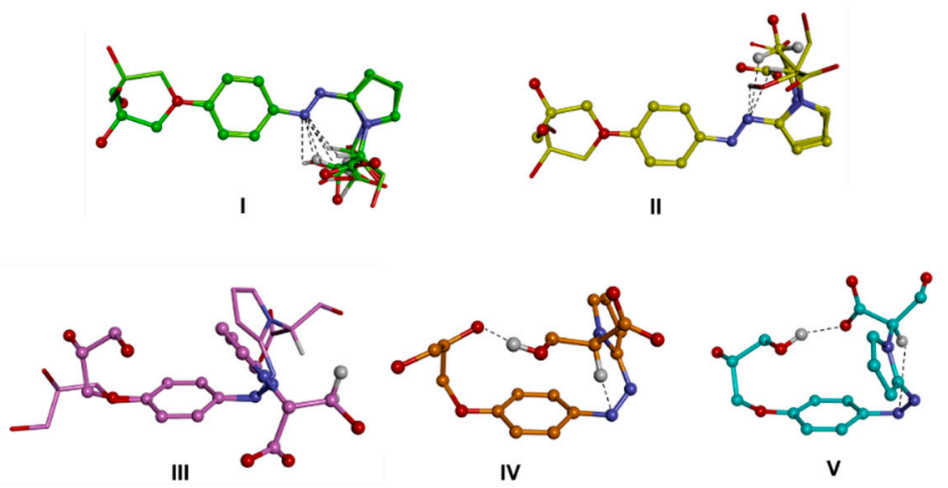

Figure 5. Conformational families of the trans (up; I,II) and cis (down; III-V) isomers of $d \mathbf{1} \mathbf{R} \mathbf{R}$ in their anionic form. The lowest energy conformer of each family is displayed as a ball and sticks. Conformers belonging to subfamilies are superimposed by phenyl ring atoms and displayed as a stick. Heteroatoms are coloured by atom type: $\mathrm{O}$, red; $\mathrm{N}$, blue. Hydrogens are omitted for clarity with the exception of those involved in intramolecular interactions (evidenced with a black dashed line).
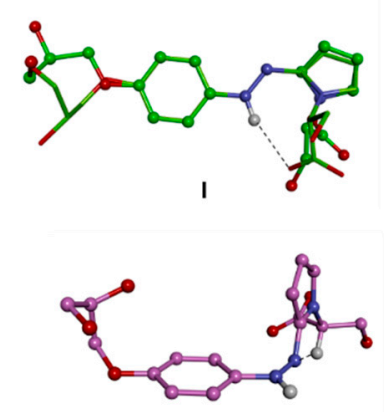

III
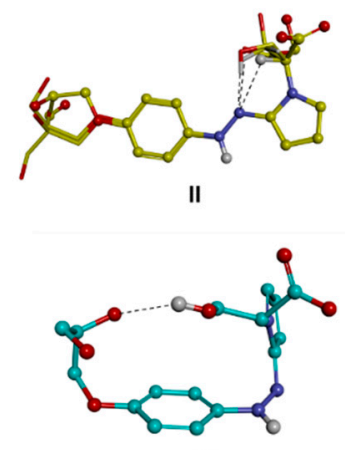

IV

Figure 6. (I-IV) conformational families of the zwitterionic form of $d \mathbf{1 R R}$. The lowest energy conformer of each family is displayed as a ball and sticks. Conformers belonging to subfamilies are superimposed by phenyl ring atoms and displayed as a stick. Heteroatoms are coloured by atom type: $\mathrm{O}$, red; N, blue. Hydrogens are omitted for clarity with the exception of those involved in intramolecular interactions (evidenced with a black dashed line).

The minima resulting from the conformational analysis on the zwitterionic form obtained after protonation (Scheme 1; Figure 6, Figure S9) assumed both the trans (families I and II) or cis (families III and IV) conformation of the NH-N bond, although with a $\Delta \mathrm{E}_{\mathrm{GM}}$ value about $4 \mathrm{kcal} / \mathrm{mol}$ in favour of the former. Moreover, in this case, the conformational families were characterized by different intramolecular interactions and were accordingly divided into sub-families (Tables S7 and S8). The GM of the two diastereomers resulted in the same sub-family (IId), presenting an intramolecular $\mathrm{H}$-bond between the unprotonated nitrogen atom of the diazo group and the hydrogen atom on the tertiary carbon of the pyrrole substituent. Surprisingly, the conformers characterized by the ionic interaction between the two charged groups of the molecule, resulted about $4 \mathrm{kcal} / \mathrm{mol}$ from the GM in both diastereomers, likely due to the value of $\tau 2$ (Tables S7 and S8, family Im) forcing the relative positioning of the pyrrole ring with respect to the $\mathrm{N}=\mathrm{N}$ bond.

Thus, to properly take into account electronic delocalization in such a conjugated system, the low energy conformers (within $5 \mathrm{kcal} / \mathrm{mol}$ from the GM) of $d \mathbf{1 R R}$ and $d \mathbf{1 R S}$ obtained by MM calculations, were, then, subjected to DFT full geometry optimization (Gaussian 09 package). The conductor-like 
polarizable continuum model (C-PCM) was used to mimic the presence of an aqueous solvent (see the experimental part for details). The resulting DFT structures were analyzed and $\Delta \mathrm{G}_{\mathrm{GM}}$ values calculated (Tables S9-S11), in addition, the length of the bonds mostly involved in electron delocalization were measured in the GM conformers (Table S12). Overall, the bond length analysis of the GM conformers indicated a higher conjugation of the diazo group with the pyrrole ring (with the bond length $\mathrm{N}-\mathrm{C}_{\mathrm{pyr}}$ closes to the double bond values) than with the phenyl-substituted ring.

The DFT GM conformers of the trans isomers (anionic form) resulted similar to those obtained by MM calculations (Tables S3 and S5 vs. Table S9), presenting the $\mathrm{N}=\mathrm{N}$ bond and the two aromatic rings lying on the same plane, thus, allowing full electron delocalization through the $\pi$ orbitals (Table S12), and an intramolecular H-bond between a nitrogen atom of the diazo group and the hydrogen atom of the secondary carbon of the substituent of the pyrrole ring. On the other contrary, the structures of the DFT conformers of the cis isomers resulted in significatively different from those obtained by MM calculations. As previously mentioned, overall, DFT results indicated a higher electronic conjugation with the pyrrole moiety than with the phenyl ring, contrarily to what observed for MM results (Tables S4 and S6 vs. Table S10). In particular, in the GM conformer, the substituted-pyrrole ring lays on the same plane of the $\mathrm{N}=\mathrm{N}$ bond, while the substituted-benzyl ring is almost orthogonal to it, differently to what resulted from MM calculations (Tables S4 and S6 vs. Table S10). The resulting T-shaped conformation, characterized by the presence of a $\mathrm{CH}-\pi$ interaction between the pyrrole and the phenyl rings, is consistent with that obtained by previous studies [19] on azoheteroarenes where one of the aromatic moieties is an ortho mono-substituted five-membered heteroaromatic ring. Importantly, it has been observed [19] that compounds adopting a T-shaped ground state of the cis isomer proceed through a T-shaped isomerization pathway, increasing the stability of the cis isomer and its isomerization half-life.

The protonation of the anionic species was simulated by adding the proton to the anionic conformers and then performing DFT optimization of the resulting zwitterionic structure. The conformers obtained were again classified according to our families/sub-families, and the $\Delta \mathrm{G}$ from the GM conformer was calculated (Table S11).

Interestingly, when we added the proton to the T-shaped GM conformer of the cis isomer, the DFT optimized structure turned in to the zwitterionic form of the trans isomer (Figure 7 and Figure S10; Table S11). Thus, protonation of the cis anionic form in its putative prevalent T-shaped conformation led to a low energy trans zwitterionic conformer, which could be, then, deprotonated to the trans isomer (Figure 7 and Figure S10). This is in line with the disappearance of the cis isomer signal $(345 \mathrm{~nm})$ in the UV spectra when the $\mathrm{pH}$ is decreased from 8 to 7 (Figure 2; Table S2) and for the overall increasing of the rate of the $c i s \rightarrow$ trans conversion by decreasing the $\mathrm{pH}$ in the fast UV experiments (Figure 4 and Figure S6).

On the other hand, the protonation of the DFT GM conformers of the trans anionic forms led to the GM conformer of the zwitterionic form, preserving the trans conformation of the parent isomer.

Taken together, our results suggest that, upon protonation (which depends on the considered $\mathrm{pH}$ conditions), either the trans and the cis isomers may convert into zwitterionic forms presenting a trans and planar conformation of the N-N bond with respect to the two aromatic substituents (Figure 7 and Figure S10). Importantly, contrarily to what resulted from MM calculations, the DFT GM conformer of the zwitterionic form is characterized by the presence of an ionic intramolecular interaction involving the two charged groups of the molecule (the protonated nitrogen atom and the carboxylate group; Figure 7 and Figure S10). It is reasonable to hypothesize that the activation energy necessary to break this intramolecular ionic interaction represents a factor strongly favoring the presence of the GM conformer of the (protonated) zwitterionic form.

In Figure $7(d \mathbf{1 R R})$ and Figure S10 $(d \mathbf{1 R S})$ a schematic representation of the putative equilibria involving the calculated DFT conformers of the ionic species possibly present in solutions in the 5.7-8.0 $\mathrm{pH}$ range, is reported. 


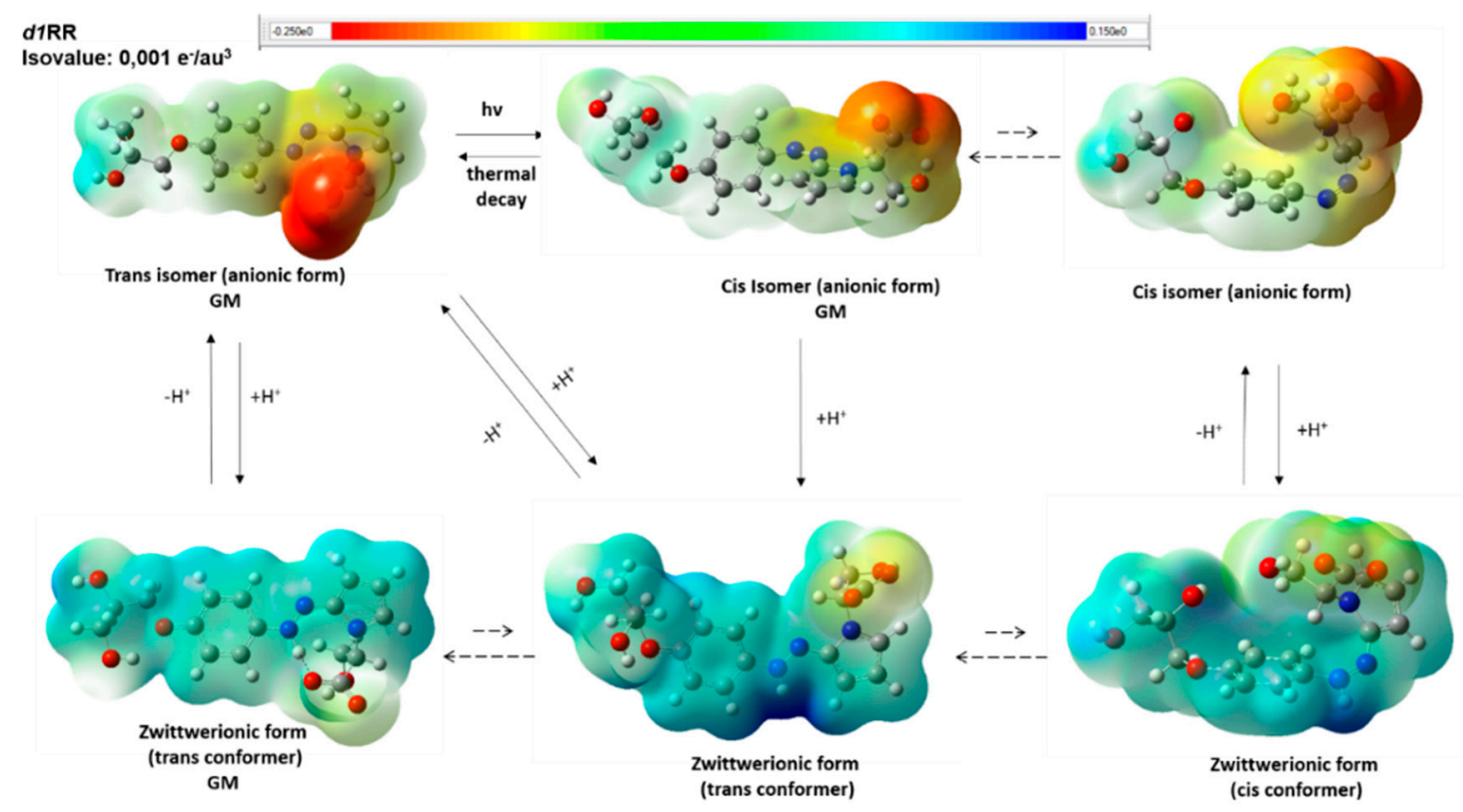

Figure 7. Putative $d \mathbf{1 R R}$ ionic species present in solution in the $\mathrm{pH}$ range considered during the fast UV experiments according to DFT calculations. Dashed arrows indicate conformational equilibria between the different conformers and GM indicate the structure of the global minimum conformer. Structures are relative to the obtained DFT minima and are displayed as a ball and sticks. Heteroatoms are coloured by atom type: $\mathrm{O}$, red; $\mathrm{N}$, blue. The molecular electrostatic potential surface is displayed.

Considering the GM structure of the zwitterionic form showed in Figure 7, it is likely that, upon carboxylate protonation, a significant amount of azonium ions would be "released" in solution. Accordingly, at $\mathrm{pH}$ values $<3.5$, the UV data showed the appearance of an additional UV band centered at about $500 \mathrm{~nm}$ (Figure S7) corresponding to diazonium ions [25-29].

\subsection{Photo-Induced Rearrangement of $d \mathbf{1 R R}$ in a Pyridazinium Ion in Acidic Buffered Solutions: The Role of the Irradiation Exposure Time}

We observed that increasing the irradiation exposure time (LED $435 \mathrm{~nm}$ ) of $d \mathbf{1 R R}$ in solution at $\mathrm{pH}=5.7$ led to an irreversible structural change of $d \mathbf{1 R R}$. Indeed, after $36-48 \mathrm{~h}$ of pulsed ( $50 \mathrm{~ms} \mathrm{ON} / 500$ ms OFF) or $18 \mathrm{~h}$ of continuous LED irradiation a strong change in the $d \mathbf{1 R R}$ UV profile appeared. In particular, the UV bands centred at $430 \mathrm{~nm}$ decreased in their intensity, whereas, new bands appeared in the UV 220-380 $\mathrm{nm}$ range (Figure 8A). Interestingly, the UV spectra acquired for $d \mathbf{1 R R}$ at different irradiation exposure times lacked the isosbestic points typical of $d \mathbf{1 R R}$ trans $\rightarrow$ cis conversion occurring in methanolic or alkaline conditions (Figure 8B). Furthermore, the UV spectrum of the irradiated $d \mathbf{1 R R}$ was not restored also taking the sample two months in the dark, thus, suggesting that the observed UV spectral changes were not attributable to $d \mathbf{1 R R}$ trans $\rightarrow$ cis conversion. In order to explore the photo-reactivity of $d \mathbf{1 R R}$ in acidic medium, the final solution was chromatographed by solid phase extraction. The column eluted with 9:1 water/methanol firstly gave two different fractions: (i) Sample 1, that showed a UV spectrum with a main band centred at about $340 \mathrm{~nm}$; and (ii) sample 2 that showed a UV spectrum similar to that of $d \mathbf{1 R R}$ (Figure 8C). Both sample $\mathbf{1}$ and $\mathbf{2}$ were further analyzed by LC-HRMS.

Preliminary experiments on an LTQ Orbitrap XL ${ }^{\text {TM }}$ Hybrid FT Mass Spectrometer system was carried out by the direct infusion of sample 1 , sample 2 and $d \mathbf{1 R R}$, with $d \mathbf{1 R R}$ used as a reference. HR full MS spectra of $d \mathbf{1 R R}$ and sample 2 appeared similar, both dominated by the $[\mathrm{M}+\mathrm{H}]^{+}$ion at $\mathrm{m} / \mathrm{z}$ $350.1344\left(\mathrm{C}_{16} \mathrm{H}_{20} \mathrm{~N}_{3} \mathrm{O}_{6}{ }^{+}\right.$Figure $\left.9 \mathrm{~A}\right)$ suggesting that sample 2 contained the unreacted $d \mathbf{1 R R}$. On the other hand, a $[\mathrm{M}+\mathrm{H}]^{+}$ion at $\mathrm{m} / \mathrm{z} 306.1453\left(\mathrm{C}_{15} \mathrm{H}_{20} \mathrm{~N}_{3} \mathrm{O}_{4}{ }^{+}\right.$, Figure $\left.9 \mathrm{~B}\right)$ emerged in the HR full MS spectrum of sample 1 indicating the presence of a new compound, differing from $d \mathbf{1 R R}$ for a $\mathrm{CO}_{2}$ 
portion less, that we named compound 1. Structural features of $d \mathbf{1 R R}$ (Figure 1) reasonably lead to hypothesize that compound $\mathbf{1}$ was originated through a photo-chemical decarboxylation reaction from d1RR [30].
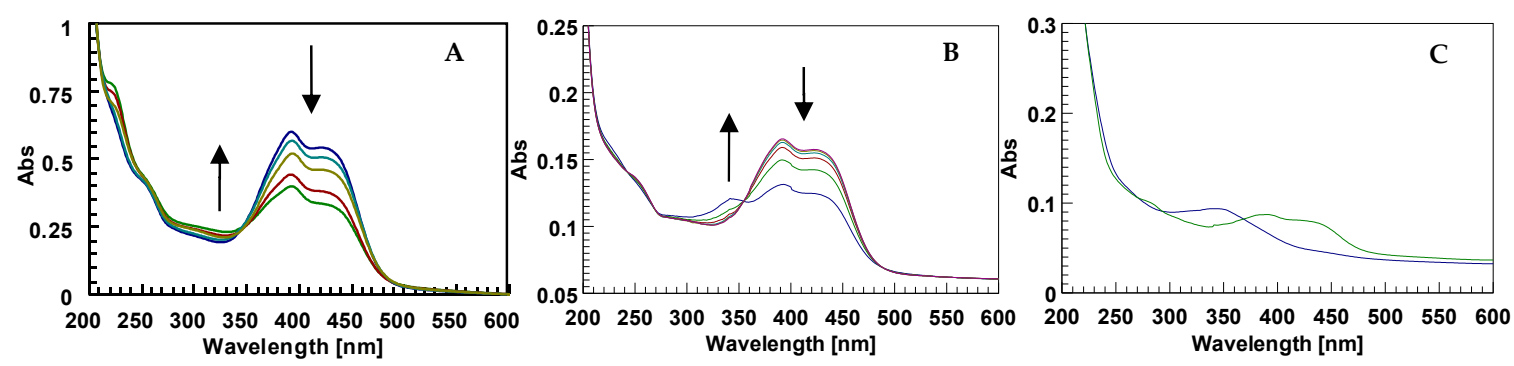

Figure 8. (A) Conversion of $d \mathbf{1 R R}$ spectrum under continuous LED irradiation at $435 \mathrm{~nm}$ at different exposure time (blue $\mathrm{t}=0$; light blue $\mathrm{t}=6 \mathrm{~h}$; yellow $\mathrm{t}=12 \mathrm{~h}$; red $\mathrm{t}=15 \mathrm{~h}$; green $\mathrm{t}=18 \mathrm{~h}$ ). (B) Cis-to-trans conversion of $d \mathbf{1 R R}$ dissolved in phosphate buffered solution at $\mathrm{pH}=8.0$ after LED irradiation (12 $\mathrm{h}$ ) at $435 \mathrm{~nm}$. The arrows show the time-evolution of the UV profile in the dark, after LED irradiation. The spectra were acquired in the dark, (red line) immediately upon irradiation (blue line) and at consecutive 2-min intervals. (C) UV spectra of sample 1 (blue line) and of sample 2 (green line).

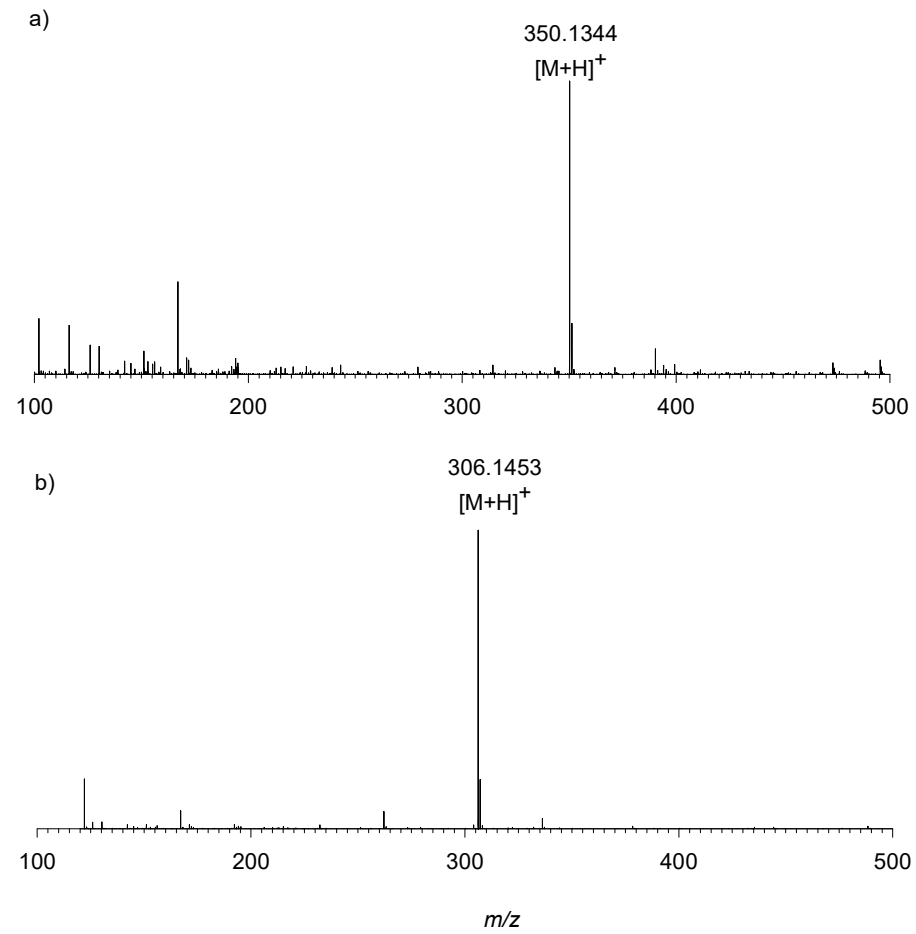

Figure 9. HRMS spectrum obtained by direct infusion of (a) $d \mathbf{1 R R}$ and (b) sample $\mathbf{1}$ on an LTQ Orbitrap XL ${ }^{\mathrm{TM}}$ Hybrid FT Mass Spectrometer.

Successively, an LC-HRMS ${ }^{n}(n=1,2)$ method was implemented by using a reverse-phase column and acidic mobile phases. Under the used experimental conditions, a chromatographic peak at 15.5 min. in the Extracted Ion Chromatogram (XIC) for the ion at $\mathrm{m} / \mathrm{z} 350.1344$ emerged for both $d \mathbf{1 R R}$ and sample 2 (Figure S11), so confirming the identity of the unmodified $d \mathbf{1 R R}$ in sample 2. Further confirmation was also obtained by the fragmentation pattern contained in the LC-HRMS 2 spectra of $\mathrm{m} / z 350.1$ of both $d \mathbf{1 R R}$ and sample 2 (Figures S11 and S12) that turned out to be superimposable the one to the other in containing two main diagnostic fragment ions at $\mathrm{m} / \mathrm{z} 195.0770$ and $\mathrm{m} / \mathrm{z} 154.0503$, deriving from the cleavage of the bond between diazo group and the pyrrole ring (Figure S13). 
A different fragmentation pattern was observed in the LC-HRMS ${ }^{2}$ spectrum of compound 1 (precursor ion at $\mathrm{m} / \mathrm{z} 306.1$, retention time $=12.7 \mathrm{~min}$ ) dominated by a main fragment ion at $\mathrm{m} / \mathrm{z} 232.1084$ $\left(\mathrm{C}_{12} \mathrm{H}_{14} \mathrm{~N}_{3} \mathrm{O}_{2}{ }^{+}\right.$, Table 2) reasonably due to the cleavage of the diol linker from the phenol oxygen (neutral loss of $\mathrm{C}_{3} \mathrm{H}_{6} \mathrm{O}_{2}$ part structure) (Figures $\mathrm{S} 14$ and S15). Basing on those results, pointing out a different fragmentation behavior between compound $\mathbf{1}$ and $d \mathbf{1 R R}$, the structural hypothesis for compound $\mathbf{1}$ being a simple decarboxylation derivative of $d \mathbf{1 R R}$, appeared not likely. Thus, the ex-novo synthesis of the derivative of $d \mathbf{1 R R}$ lacking of the carboxylic group (compound 2) was accomplished (Figure 10).

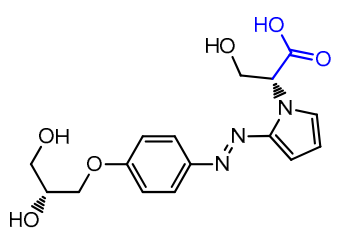

$d \mathbf{R R}$

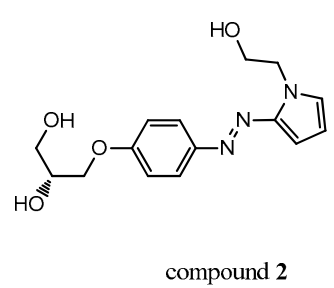

Figure 10. Chemical structure of $d \mathbf{1 R R}$ and of the synthesized decarboxylate derivative, named compound 2.

HRMS and HRMS ${ }^{2}$ experiments acquired for compound 2 (Figure S16) highlighted a fragmentation pattern similar to that observed for $d \mathbf{1 R R}$ (Figure S12), dominated by a main fragment ion at $\mathrm{m} / \mathrm{z} 195.0773$, suggesting that compound $\mathbf{1}$, although sharing the same elemental composition with compound $\mathbf{2}$, should be a constitutional isomer.

In order to clarify the structure of compound 1, we performed 1D and 2D NMR spectroscopy (Figures S17-S21).

Figure 11B shows the two patterns of aromatic proton signals in $d \mathbf{1 R R}$. The two doublets at 7.20 and $7.55 \mathrm{ppm}$ are attributable to the resonances of protons on benzene ring, whereas, the three signals at $6.31,6.65,7.29 \mathrm{ppm}$ to that on the pyrrole ring (for more detailed information see reference [20]). Only a little shift of the proton signal at 7.29 was observed in the ${ }^{1} \mathrm{H}$ spectrum of compound 2 (Figure 11A and Figure S20). On the other hand, comparing ${ }^{1} \mathrm{H}$ NMR data acquired on $d \mathbf{1 R R}$ with that obtained on compound 1 (Figure 11C) three main differences were observed: (i) A down-field shift of the proton resonances on benzene ring (7.98 and $7.20 \mathrm{ppm}$ ); (ii) the loss of the signals of the protons on pyrrole ring; (iii) a new set of three proton signals at 9.26, 8.02, and $7.62 \mathrm{ppm}$. As in the case of $d \mathbf{1 R R}$, in the aromatic region of the ${ }^{1} \mathrm{H}^{1}{ }^{1} \mathrm{H}$ COSY spectrum three scalar couplings (7.98 and 7.20; 9.26 and 8.02, and 8.02 and $7.62 \mathrm{ppm}$ ) were observed (Figure S18). These data suggested that in compound 1, a new, deshielding, chemical environmental surrounded most of the aromatic protons.

Hence, the UV profiles, the fragmentation pattern (Table 2) and the aromatic proton resonances of compound 1 strongly suggested that the prolonging in LED irradiation time of $d \mathbf{1 R R}$ in acidic conditions promotes a rearrangement of the diazo-aromatic core of the molecule that also involves a decarboxylation reaction.

We hypothesized that the diazo group and the pyrrole ring could rearrange, under irradiation, in a pyridazinium salt (Figure 12). This type of structure well fit with: (i) The blue shift of the UV band observed for compound $\mathbf{1}$ [31] respect to $d \mathbf{1 R R}$; (ii) the fragmentation pattern contained in HRMS ${ }^{2}$ spectrum (Figure S11C) and; (iii) the $\Delta \delta$ between the aromatic proton signals in $d \mathbf{1 R R}$ and compound 1 [32]. Despite more detailed studies should be performed to clarify better the exact reaction pathway, based on recently published data [32,33], we hypothesized that in acidic conditions a reaction similar to that described by Fehler et al. [32] could occur. Studies on the exact mechanism are currently in progress. 
Table 2. Assignment of fragment ions contained in the HR CID MS ${ }^{2}$ spectrum of compound 1. Elemental formulae of the mono-isotopic ion peaks $(\mathrm{m} / \mathrm{z})$ are reported with double bond/ring equivalents (RDB) and errors $(\Delta, \mathrm{ppm})$.

\begin{tabular}{|c|c|c|c|}
\hline $\operatorname{Exp}$. MS $(m / z)$ & $\Delta$ ppm, RDB & Formula & Structural hypothesis \\
\hline \multicolumn{4}{|c|}{ Precursor ion } \\
\hline 306.1457 & $2.833,7.5$ & $\mathrm{C}_{15} \mathrm{H}_{20} \mathrm{~N}_{3} \mathrm{O}_{4}^{+}$ & \\
\hline \multicolumn{4}{|c|}{ Fragment ions } \\
\hline 288.1351 & $2.888,8.5$ & $\mathrm{C}_{15} \mathrm{H}_{18} \mathrm{~N}_{3} \mathrm{O}_{3}{ }^{+}$ & \\
\hline 275.1274 & $3.479,8.0$ & $\mathrm{C}_{14} \mathrm{H}_{17} \mathrm{~N}_{3} \mathrm{O}_{3} \cdot+$ & \\
\hline 232.1084 & $1.494,7.5$ & $\mathrm{C}_{12} \mathrm{H}_{14} \mathrm{~N}_{3} \mathrm{O}_{2}^{+}$ & \\
\hline 262.1193 & $2.602,7.5$ & $\mathrm{C}_{13} \mathrm{H}_{16} \mathrm{~N}_{3} \mathrm{O}_{3}{ }^{+}$ & \\
\hline 247.1083 & $2.352,7.05$ & $\mathrm{C}_{13} \mathrm{H}_{15} \mathrm{~N}_{2} \mathrm{O}_{3}{ }^{+}$ & \\
\hline 220.0975 & $3.090,6.5$ & $\mathrm{C}_{12} \mathrm{H}_{14} \mathrm{NO}_{3}{ }^{+}$ & \\
\hline 214.0981 & $2.856,8.5$ & $\mathrm{C}_{12} \mathrm{H}_{12} \mathrm{~N}_{3} \mathrm{O}^{+}$ & \\
\hline 204.1138 & $3.240,6.5$ & $\mathrm{C}_{11} \mathrm{H}_{14} \mathrm{~N}_{3} \mathrm{O}^{+}$ & \\
\hline 188.0824 & $2.985,7.5$ & $\mathrm{C}_{10} \mathrm{H}_{10} \mathrm{~N}_{3} \mathrm{O}^{+}$ & \\
\hline 173.0714 & $2.661,7.5$ & $\mathrm{C}_{10} \mathrm{H}_{9} \mathrm{~N}_{2} \mathrm{O}^{+}$ & \\
\hline 159.0683 & $2.732,7.0$ & $\mathrm{C}_{10} \mathrm{H}_{9} \mathrm{NO}^{\bullet+}$ & \\
\hline 146.0604 & $2.462,6.5$ & $\mathrm{C}_{9} \mathrm{H}_{8} \mathrm{NO}^{+}$ & \\
\hline 108.0445 & $1.015,4.5$ & $\mathrm{C}_{6} \mathrm{H}_{6} \mathrm{NO}^{+}$ & \\
\hline
\end{tabular}


A

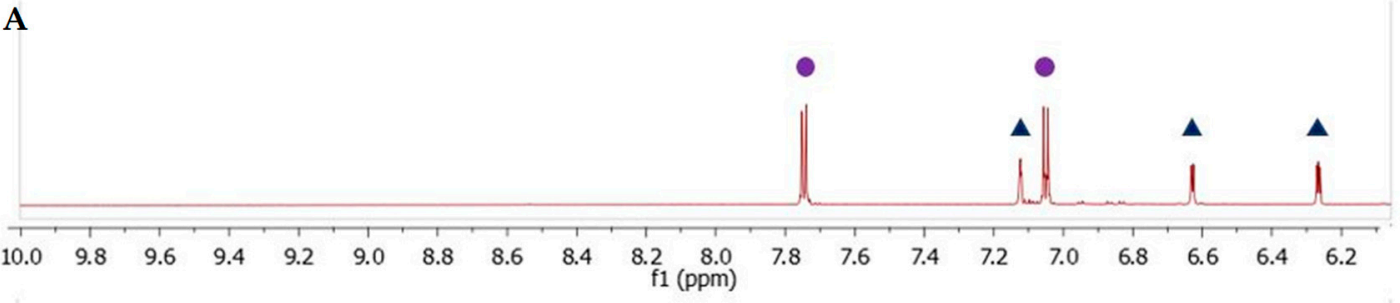

B

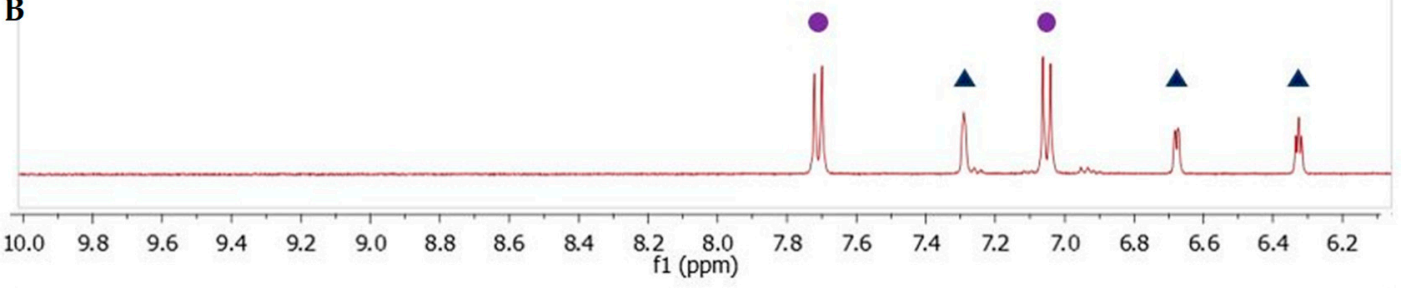

C

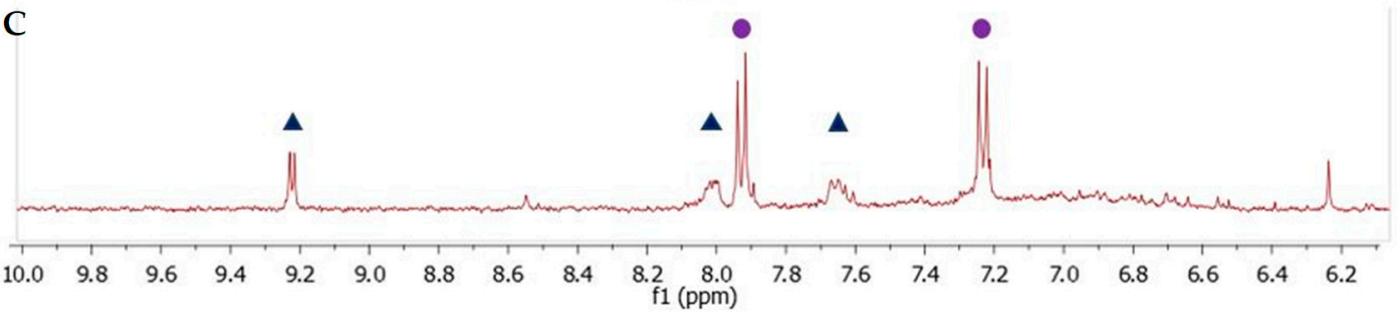

Figure 11. The aromatic region of ${ }^{1} \mathrm{H}$ NMR spectra of compound $\mathbf{2}(\mathbf{A}), d \mathbf{1 R R}(\mathbf{B})$, compound $\mathbf{1}(\mathbf{C})$. Full circles show the proton on phenyl ring in all species, whereas, the triangles in $(\mathbf{A}, \mathbf{B})$ indicate the proton resonances attributable to the hydrogen on pyrrole ring and the triangles in $(\mathbf{C})$ the pattern of new proton signals in compound $\mathbf{1}$.<smiles></smiles>

Figure 12. Hypothesized chemical structure of compound 1.

\section{Materials and Methods}

\subsection{General}

Commercial reagents, all organic solvents and water (HPLC grade), formic acid (95-97\%, Laboratory grade), and ammonium formate (AR grade) were purchased from Sigma-Aldrich (Steinheim, Germany).

TLCs were run on Merck silica gel 60 F254 plates (Kenilworth, NJ, USA) and the spots were visualized by means of a UV lamp (Vilber Lourmat VL-4LC, 365 and $254 \mathrm{~nm}$ ). Silica gel chromatography was performed using Merck silica gel $60(0.063-0.200 \mathrm{~mm})$. UV experiments were performed on a JASCO V-530 spectrophotometer, equipped with a PTC-348 temperature controller. ${ }^{1} \mathrm{H}(500 \mathrm{MHz}$ and $400 \mathrm{MHz})$ and ${ }^{13} \mathrm{C}(125 \mathrm{MHz}$ and $100 \mathrm{MHz})$. NMR spectra were recorded on an Agilent INOVA spectrometer (Agilent Technology, Cernusco sul Naviglio, Italy) [34-36]; chemical shifts were referenced to the residual solvent signal $\left(\mathrm{CD}_{3} \mathrm{OD}: \delta_{\mathrm{H}}=3.31, \delta_{\mathrm{C}}=49.0 \mathrm{ppm}, \mathrm{CDCl}_{3}: \delta_{\mathrm{H}}=7.26, \delta_{\mathrm{C}}=77.0 \mathrm{ppm}\right)$. For an accurate measurement of the coupling constants, the one-dimensional ${ }^{1} \mathrm{H}$ NMR spectra were transformed at $64 \mathrm{~K}$ points (digital resolution: $0.09 \mathrm{~Hz}$ ). ${ }^{1} \mathrm{H}$ connectivities were determined by COSY (mixing time $100 \mathrm{~ms}$ ). 


\subsection{Chemistry}

Compounds $d \mathbf{1 R R}$ and $d \mathbf{1 R S}$ were obtained by hydrolysis of the corresponding methyl esters 1RR and 1RS [20] respectively (scheme S1). The synthesis of compound $\mathbf{2}$ was performed according to Scheme S1. The pyrrole derivative VI used in the diazo-coupling reaction was obtained from acetylation of the 2-pyrrol-1-yl-ethanol (V) [37]. The ${ }^{1} \mathrm{H}$ and ${ }^{13} \mathrm{C}$ NMR spectra of compound 2 was reported in Figures S20 and S21.

2-Pyrrol-1-yl-ethanol (V). A stirred solution of 2,5-dimethoxytetrahydrofuran (2.04 g, $15.4 \mathrm{mmol})$ in $\mathrm{H}_{2} \mathrm{O}(20 \mathrm{~mL})$ was heated at reflux under $\mathrm{N}_{2}$. After $2 \mathrm{~h}$ the reaction mixture was cooled to room temperature, and then a solution of ethanolamine $(1.13 \mathrm{~g}, 18.5 \mathrm{mmol})$ in dichloromethane $(30 \mathrm{~mL})$ was added. The reaction mixture was stirred vigorously in the dark overnight, and then the organic phase was separated. The aqueous phase was re-extracted with dichloromethane $(3 \times 20 \mathrm{~mL})$, and the combined organic layers were dried over sodium sulfate, filtered and concentrated under reduced pressure. The resulting residue was purified by flash chromatography $\left(\mathrm{SiO}_{2}\right.$, eluted with dichloromethane) to give the title compound as a colourless oil. Yield: $62 \%$.

${ }^{1} \mathrm{H}$ NMR $\left(400 \mathrm{MHz}, \mathrm{CDCl}_{3}\right) \delta: 3.86(\mathrm{t}, 2 \mathrm{H}, J=5.2 \mathrm{~Hz}), 4.03(\mathrm{t}, 2 \mathrm{H}, J=5.2 \mathrm{~Hz}), 6.18(\mathrm{t}, 2 \mathrm{H}, J=2.2 \mathrm{~Hz})$, $6.71(\mathrm{t}, 2 \mathrm{H}, J=2.2 \mathrm{~Hz}) .{ }^{13} \mathrm{C} \mathrm{NMR}\left(\mathrm{CDCl}_{3}, 100 \mathrm{MHz}\right) \delta: 51.9,62.9,108.6,120.8$.

Acetic acid 2-pyrrol-1-yl-ethyl ester (VI). N,N-Diispropylethylamine $(1.57 \mathrm{~g}, 12.1 \mathrm{mmol})$ and acetic anhydride $(1.65 \mathrm{~g}, 16.2 \mathrm{mmol})$ was added to a solution of $\mathbf{V}(0.90 \mathrm{~g}, 8.10 \mathrm{mmol})$ in dichloromethane $(10 \mathrm{~mL})$, and the resulting reaction mixture was stirred at room temperature. After $15 \mathrm{~h}$ the reaction mixture was washed with brine $(2 \times 20 \mathrm{~mL})$, and the organic phase was dried over sodium sulfate, filtered and concentrated in vacuo. Then, the resulting residue was purified by flash chromatography $\left(\mathrm{SiO}_{2}\right.$, dichloromethane/ $n$-hexanes $4: 1$ as eluent) to give $\mathrm{VI}$ as a colourless oil. Yield $73 \%$.

${ }^{1} \mathrm{H}$ NMR $\left(400 \mathrm{MHz}, \mathrm{CDCl}_{3}\right) \delta: 2.06(\mathrm{~s}, 3 \mathrm{H}), 4.13(\mathrm{t}, 2 \mathrm{H}, J=5.6 \mathrm{~Hz}), 4.32(\mathrm{t}, 2 \mathrm{H}, J=5.6 \mathrm{~Hz}), 6.17(\mathrm{t}$, $2 \mathrm{H}, J=2.2 \mathrm{~Hz}), 6.68(\mathrm{t}, 2 \mathrm{H}, J=2.2 \mathrm{~Hz}) .{ }^{13} \mathrm{C} \mathrm{NMR}\left(\mathrm{CDCl}_{3}, 100 \mathrm{MHz}\right) \delta: 20.8,48.2,64.0,108.5,120.8$, 170.6 .

Compound 1. A phosphate buffered solution of $d \mathbf{1 R R}$ at $\mathrm{pH}=5.7\left(8.0 \times 10^{-3} \mathrm{mg} / \mathrm{L}\right)$ was irradiated for $18 \mathrm{~h}$ with pulse-program ( $50 \mathrm{~ms}-\mathrm{ON} / 1.0 \mathrm{~min}$-OFF by means of an Arduino module to manage the LED plate at $435 \mathrm{~nm}$ ). Then the solution was chromatographed on RP-18 cartridge (Oasis HLB) by means of Manifold vacuum system (Phenomenex). The cartridge was washed with water, loaded with the reaction mixture and eluted with a gradient of methanol in water. The collected fractions were analyzed by UV spectroscopy, and those containing compound 1 subjected to MS, MS ${ }^{2}$ spectrometry and NMR spectroscopy (Figures S14-S15, and Figures S17-S19). The same experiment was also performed using two phosphate buffered solutions of $d \mathbf{1 R R}$ at $\mathrm{pH}=7.0$ and 8.0. In these cases, no significant changes in the UV spectrum of $d \mathbf{1 R R}$ were obtained.

\subsection{UV Spectroscopy}

UV experiments were performed in phosphate buffer $(0.1 \mathrm{M})$ at $\mathrm{pH}=8.0,7.5,7.0,6.7,6.5,6.0$ and 5.7. All samples of $d \mathbf{1 R R}$ or $d \mathbf{1 R S}$ were used at a final concentration of $80 \mu \mathrm{M}$. o.l. cuvette $0.5 \mathrm{~cm}$. In order to acquire the UV spectra before the LED irradiation, the samples were kept in the dark for $24 \mathrm{~h}$. UV spectra of the cis isomers were acquired after irradiation of the samples at $435 \mathrm{~nm}$ (1 min, 1 LED $435 \mathrm{~nm}$ Roithner Lasertechnik). The cis thermal decay was monitored by the further sequential acquisition of spectra (every $1.0 \mathrm{~min}$ ) until the UV profile became that of the initial trans isomer.

\subsection{Fast UV Spectroscopy}

Figure S2 reports a sketch of the experimental setup for the fast UV spectroscopy. The light source was a Deuterium arc lamp, delivering a board emission band down to about $200 \mathrm{~nm}$. This acted as the probe to monitor the transient absorption spectra of the sample.

Several optical filters were used to adjust the spectrum and the average power of the probe, preventing any perturbation of the sample by the probe light. A couple of UV-grade convex lenses 
were used to collimate diverging output light of the lamp, and finally, it was coupled to an optical fiber that carried the light to the detector. The cuvette was kept between the two lenses, and collimated probe light passed through the sample. The detector was a spectrograph combined with an intensified CCD (ICCD), which was recording the transmitted light at a repetition rate of 10 or $25 \mathrm{~Hz}$; the latter being used for the faster processes in acidic solutions.

A portion of the same samples analyzed by UV spectroscopy was used in the experiments. $1.8 \mathrm{~mL}$ of the sample was held in a quartz cuvette, and stirred by a magnetic stirrer. The absorption spectrum of the sample in $10 \mathrm{~mm}$ optical path was monitored in the $220-430 \mathrm{~nm}$ spectral range; resulting $2 \mathrm{D}$ plots of changes in absorption spectrum versus time.

Kinetic measurements were performed by means of fast UV spectroscopy for photo-conversion of the trans to the cis isomers, together with those for the reverse reactions in the dark.

\subsection{Liquid Chromatography_High Resolution Mass Spectrometry}

LC-HRMS experiments were carried out on Dionex Ultimate 3000 system which included a solvent reservoir, in-line degasser, quaternary pump and refrigerated autosampler and column oven, coupled to a hybrid linear ion trap LTQ Orbitrap XL ${ }^{\text {TM }}$ Fourier Transform MS (FTMS) equipped with an ESI ION MAX ${ }^{\mathrm{TM}}$ source (Thermo-Fisher, San Josè, CA, USA). Chromatographic separation was accomplished by using a Poroshell 120 EC-C18, $2.7 \mu \mathrm{m}, 2.1 \times 100 \mathrm{~mm}$ column (Agilent, Santa Clara, CA, USA) maintained at room temperature and eluted at $0.2 \mathrm{~mL} / \mathrm{min}$ with water (eluent A) and $95 \%$ acetonitrile/water (eluent B), both containing $2 \mathrm{mM}$ ammonium formate and $50 \mathrm{mM}$ formic acid. A gradient elution was used-3\% B hold for the first $5 \mathrm{~min}, 3-30 \%$ B over $5 \mathrm{~min}, 30-70 \%$ B over $5 \mathrm{~min}$, $70-100 \%$ B in further $5 \mathrm{~min}$ and hold for $4 \mathrm{~min}$. Injection volume was $5 \mu \mathrm{L}$ in all cases.

HR full MS experiments (positive ions) were carried out in the mass ranges $m / z$ 100-1000 at a resolving power of 30,000 ( $\mathrm{m} / z$ 400). Source settings were optimized by using $d \mathbf{1} \mathbf{R} \mathbf{R}$ as reference standard and used in all the experiments: A spray voltage of $4.8 \mathrm{kV}$, a capillary temperature of $275^{\circ} \mathrm{C}$, a capillary voltage of $13 \mathrm{~V}$, a sheath gas and an auxiliary gas flow of 51 and 1 (arbitrary units), respectively, and a tube lens voltage of $80 \mathrm{~V}$.

HRMS $^{2}$ data were acquired by selecting the $[\mathrm{M}+\mathrm{H}]^{+}$ion at $\mathrm{m} / \mathrm{z} 350.1$ and $\mathrm{m} / \mathrm{z} 306.1$ and fragmenting them through collision-induced dissociation (CID) with collision energy (CE) of 30\% and $42 \%$, respectively. Activation $Q$ was set at 0.250 , and an activation time of $30 \mathrm{msec}$ was used.

Elemental formulae of ions contained in HRMS and HRMS ${ }^{2}$ spectra were assigned by using the mono-isotopic ion peak of each ion cluster and the Xcalibur 2.2 software setting a mass tolerance of 5 ppm.

\subsection{Molecular Modeling}

Molecular modeling calculations were performed on E4 Server Twin $2 \times$ Dual Xeon-5520, equipped with two nodes. Each node: $2 \times$ Intel ${ }^{\circledR}$ Xeon ${ }^{\circledR}$ QuadCore E5520-2.26Ghz, 36 GB RAM. The molecular modeling graphics were carried out on a personal computer equipped with Intel(R) Core(TM) i7-4790 processor and SGI Octane 2 workstations.

The apparent pKa values of $d \mathbf{1 R R}$ and $d \mathbf{1 R S}$ were calculated by using the ACD/Percepta software (ACD/Percepta, Advanced Chemistry Development, Inc., Toronto, ON, Canada, 2017, http://www. acdlabs.com). The percentage of neutral/ionized forms present at the $\mathrm{pH}$ values used in the experimental studies (i.e., range 5.7-8.0) were computed using the Handerson-Hasselbach equation. The resulting species were built and subjected to molecular mechanic $(\mathrm{MM})$ energy minimization $(\varepsilon=80 \times \mathrm{r})$ until the maximum RMS derivative was less than $0.001 \mathrm{kcal} / \AA$, using Conjugate Gradient as minimization algorithm (Discovery Studio 2017; Dassault Systèmes BIOVIA, San Diego, 2017) [38]. Atomic potentials and charges were assigned using the CFF forcefield [39]. The conformers obtained for each compound were used as the starting structure for the subsequent systematic conformational analysis (Search Small Molecule Conformations; Discovery Studio 2017). 
All the generated structures were then subjected to a systematic conformational search procedure. The conformational space was sampled by systematically varying the single bonds with an increment of $60^{\circ}$, as well as the double bonds with an increment of $180^{\circ}$. The RMSD cutoff for structure selection was set to $0.01 \AA$ A. Finally, to ensure a wide variance of the input structures to be successively fully minimized, an energy threshold value of $10^{6} \mathrm{kcal} / \mathrm{mol}$ was used as selection criteria. The generated structures were then subjected to MM energy minimization both in a vacuum and aqueous environment $(\varepsilon=1$ and $\varepsilon=80 \times \mathrm{r}$, respectively) until the maximum RMS derivative was less than $0.001 \mathrm{kcal} / \AA$, using Conjugate Gradient as minimization algorithm. Finally, the resulting conformers were ranked by their potential energy values (i.e., $\Delta \mathrm{E}$ from the global energy minimum $(\mathrm{GM}))$. All MM conformers $(\varepsilon=80 \times \mathrm{r})$ within $5 \mathrm{kcal} / \mathrm{mol}$ from the global minimum $\left(\Delta \mathrm{E}_{\mathrm{GM}} \leq 5 \mathrm{kcal} / \mathrm{mol}\right)$ were analyzed and grouped into families, named $\mathrm{I}-\mathrm{V}$, according to the values of the dihedral angles $\tau 1$ and $\tau 2$. The resulting families were then divided into subfamilies (named a-n) on the basis of the observed intramolecular interactions.

The global minimum conformers $(\varepsilon=1$ and $\varepsilon=80 \times \mathrm{r}$ ) of each species, as well as the lowest energy conformers of the families presenting the highest number of conformers $(\varepsilon=80 \times \mathrm{r})$ have been subjected to DFT full geometry optimization. The calculations were carried out using the Gaussian 09 package [40]. All structures were fully optimized at the B3LYP/6-31+G(d,p) level $[41,42]$ using the conductor-like polarizable continuum (C-PCM) model, which allows the calculation of the energy in the presence of a solvent [43]. In this case, all structures were optimized as a solute in an aqueous solution. In order to characterize every structure as minimum and to calculate the Gibbs free energy, a vibrational analysis was carried out at the same level of theory using the keyword freq. The RMS force criterion was set to $3 \times 10^{-4}$ a.u. Partial charges have been calculated using the natural bond orbital (NBO) method [44].

\section{Conclusions}

Through the use of UV and UV fast spectroscopy the kinetic behavior of the trans $\leftrightarrow$ cis isomerizations of two azoheteroarenes, named $d \mathbf{1 R R} / d \mathbf{1 R S}$ has been studied, using phosphate (0.1M) solutions buffered at different $\mathrm{pH}$ (from 8.0 to 5.7). The results evidenced at least two important features.

First of all, the increasing of the proton concentration provoked a general increase in the rates of

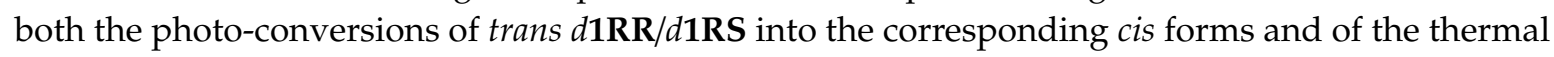
decay of cis $d \mathbf{1 R R} / d \mathbf{1 R S}$. According to literature data, the protonation of the diazo group of $d \mathbf{1 R R} / d \mathbf{1 R S}$ should occur in the solution [25-29].

The computational analysis of the conformational preference of the calculated species present in solution in the $\mathrm{pH}$ range 5.7-8.0 highlighted that while the trans isomer preferentially adopts a fully planar and conjugated conformation, the cis isomer is characterized by a T-shaped conformation. Importantly, it has been reported that azoheteroarene photoswitches able to adopt a T-shaped ground state conformation of the cis isomer are characterized by longer half-lives [19]. Noteworthy, upon protonation both the trans and the cis isomers resulted in the formation of a zwitterionic form characterized by a trans and planar conformation and stabilized by ionic intramolecular interaction between the two charged groups. Thus, our results indicate that protonation of $d \mathbf{1 R R} / d \mathbf{1 R S}$ can strongly affect their ground state conformation increasing the rate of trans $\leftrightarrow$ cis isomerizations. Second, the results of fast UV experiments also showed that for both of the two stereomers, $d \mathbf{1 R R} / d \mathbf{1 R S}$, the pKa values of the cis and trans isomers should be slightly different. Indeed, the kinetic measurements performed at 400 (a band of the trans isomers) and $340 \mathrm{~nm}$ (a band of the cis stereomers) gave rise to two different trends of the apparent rate constants versus $\mathrm{pH}$.

The investigation on $d \mathbf{1 R R} / d \mathbf{1 R S}$ photo-responsive properties also showed that $d \mathbf{1 R R}$, but not d1RS underwent to a photo-transformation under prolonged irradiation. The characterization of the final molecule produced in this condition led to the identification of a new pyridazinium salt. Interestingly, the pyridazinium salt is formed only from highly diluted solution buffered at $\mathrm{pH}=5.7$, thus, suggesting that the mechanism of the reaction should be monomolecular and that the reaction should be promoted by the presence of $d \mathbf{1 R R}$ diazonium ions in solution. Despite further studies 
are necessary to establish the exact way of this reaction, the different behavior of $d \mathbf{1 R R}$ and $d \mathbf{1 R S}$ under prolonged reaction herein reported could be the reason of the previously reported different dose-response antiproliferative action of $\mathbf{1 R R}, \mathbf{1 R S}$ and their mixture [20].

Supplementary Materials: Supplementary materials can be found at http://www.mdpi.com/1422-0067/21/4/1246/ s1. Figure S1. UV spectra of $d \mathbf{1 R S}$ in the dark at different $\mathrm{pH}$, Figure S2. A schematic representation of the instrument employed for fast UV spectroscopy, Figure S3. Cis to trans thermal conversion for $d \mathbf{1 R R}$, Figure S4. Cis to trans and trans to cis conversion for $d \mathbf{1 R R}$ at pH 5.7 and 7.0, Figure S5. Cis to trans and trans to cis conversion for $d \mathbf{1 R S}$ at $\mathrm{pH} 5.7$ and 7.0, Figure S6. Changes in apparent rate constant $\left(k_{\mathrm{obs}}\right)$ in the $\mathrm{pH}$ range 5.7-8.0, Figure S7. $\mathrm{UV}$-vis spectra of $d \mathbf{1 R R}$ and $d \mathbf{1 R S}$ in the $\mathrm{pH}$ range 7.0-1.5, Figure S8. Conformational families of trans (I-II) and cis (III-V) isomers of $d \mathbf{1 R S}$, Figure S9. Conformational families of the zwitterionic form of $d \mathbf{1 R S}$, Figure S10. Putative d1RS ionic species present in solution, Figure S11. LC-HRMS of sample 2: (A) Extracted ion Chromatogram at $m / z$ 350.1344, (B) associated HRMS spectrum and (C) associated HRMS ${ }^{2}$ spectra, Figure S12. HRMS ${ }^{2}$ spectrum of $d \mathbf{1 R R}$ obtained by using the ion at $m / z 350.1$ as precursor, Figure S13. The cleavage occurring for $d \mathbf{1 R R}$ in HRMS ${ }^{2}$ experiments giving rise to two main fragment ions, Figure S14. LC-HRMS of compound 1: (A) Extracted ion Chromatogram at $m / z 306.1453$ (B) associated HRMS and (C) HRMS ${ }^{2}$ spectra, Figure S15. Enlargement range of the LC-HRMS ${ }^{2}$ spectrum of the precursor ion of compound 1, Figure S16. HRMS and HRMS ${ }^{2}$ spectra of compound 2 , Figure S17. ${ }^{1} \mathrm{H}$ NMR spectrum of compound 1 in $\mathrm{CD}_{3} \mathrm{OD}$, Figure S18. Low-field enlargement of ${ }^{1} \mathrm{H}_{-}{ }^{1} \mathrm{H}$ COSY NMR spectrum of compound 1 in $\mathrm{CD}_{3} \mathrm{OD}$, Figure S19. High-field enlargement of ${ }^{1} \mathrm{H}_{-}{ }^{1} \mathrm{H}$ COSY NMR spectrum of compound 1 in $\mathrm{CD}_{3} \mathrm{OD}$, Figure S20. ${ }^{1} \mathrm{H}$ NMR spectrum of compound 2 in $\mathrm{CD}_{3} \mathrm{OD}$. Figure S21, ${ }^{13} \mathrm{C}$ NMR spectrum of compound 2 in $\mathrm{CD}_{3} \mathrm{OD}$, Table S1. Data coming from the interpolation of the apparent rate constants versus [ $\left.\mathrm{H}^{+}\right]$, Table S2. Calculated percentages of ionic species of $d \mathbf{1 R R}$ and $d \mathbf{1 R S}$ in the $\mathrm{pH}$ range 1.0-8.0, Table S3. $\Delta \mathrm{E}_{\mathrm{GM}}$ values and torsion angle values of the MM conformers of trans isomer of $d \mathbf{1 R R}$, Table S4. $\Delta \mathrm{E}_{\mathrm{GM}}$ values and torsion angle values of the MM conformers of cis isomer $d \mathbf{1 R R}$, Table S5. $\Delta \mathrm{E}_{\mathrm{GM}}$ values and torsion angle values of the MM conformers of trans isomer of $d \mathbf{1 R S}$, Table $\mathrm{S} 6 . \Delta \mathrm{E}_{\mathrm{GM}}$ values and torsion angle values of the MM conformers of $c i$ isomer $d \mathbf{1 R S}$, Table S7. $\Delta \mathrm{E}_{\mathrm{GM}}$ values and torsion angle values of the MM conformers of $d \mathbf{1 R R}$ in the zwitterionic form, Table S8. $\Delta \mathrm{E}_{\mathrm{GM}}$ values and torsion angle values of the MM conformers of $d \mathbf{1 R S}$ in the zwitterionic form, Table S9. $\Delta \mathrm{G}_{\mathrm{GM}}$ values and torsion angle values of the DFT trans isomers of $d \mathbf{1 R S}$ and $d \mathbf{1 R R}$ in the anionic form, Table S10. $\Delta \mathrm{G}_{\mathrm{GM}}$ values and torsion angle values of the DFT cis isomer of $d \mathbf{1 R S}$ and $d \mathbf{1 R R}$ in the anionic form, Table S11. $\Delta \mathrm{G}_{\mathrm{GM}}$ values and torsion angle values of the DFT conformers of $d \mathbf{1 R S}$ and $d \mathbf{1 R R}$ in the zwitterionic form, Table S12. Bond length values $(\AA)$ of the DFT conformers of $d \mathbf{1 R R}$ and $d \mathbf{1 R S}$, Scheme S1. Synthesis of compound 2.

Author Contributions: Conceptualization, C.F., C.A. and M.V. (Michela Varra); Data curation, C.I., M.V. (Mohammadhassan Valadan), L.T., M.P., M.S., F.B., M.C., M.L.d.G., A.R., E.M. and M.V. (Michela Varra); Formal analysis, C.D., M.M., C.F., C.A. and M.V. (Michela Varra); Funding acquisition, M.M., C.D., C.A., M.V. (Michela Varra) and A.R.; Investigation, C.I., M.V. (Mohammadhassan Valadan), L.T., M.P., A.R., M.C., M.S., F.B., M.L.d.G. and E.M.; Methodology, C.F., M.M., C.D., C.A. and M.V. (Michela Varra); Supervision, C.F., C.D., A.R., M.M., C.A. and M.V. (Michela Varra); Writing_original draft, C.I., M.V. (Mohammadhassan Valadan), C.F., C.A. and M.V. (Michela Varra); Writing — review and editing, all authors contributed to the review \& editing of the final manuscript version. All authors have read and agreed to the published version of the manuscript.

Funding: This work was supported by a grant from Regione Campania-POR Campania FESR 2014/2020 "Combattere la resistenza tumorale: piattaforma integrata multidisciplinare per un approccio tecnologico innovativo alle oncoterapie-Campania Oncoterapie" (Project N. B61G18000470007), and by the Italian Minister for Research under the Project PRIN-Predicting and controlling the fate of bio-molecules driven by extreme-ultraviolet radiation (Prot. N. 20173B72NB).

Acknowledgments: The authors are greateful to "Istituto Tecnico Industriale Statale Francesco Giordani of Caserta" (I.T.I.S. Giordani) for their technical assistance on the LED system construction.

Conflicts of Interest: The authors declare no conflict of interest.

\section{References}

1. Pianowski, Z.L. Recent Implementations of Molecular Photoswitches into Smart Materials and Biological Systems. Chem. Eur. J. 2019, 25, 5128-5144. [CrossRef] [PubMed]

2. Kathan, M.; Hecht, S. Photoswitchable molecules as key ingredients to drive systems away from the global thermodynamic minimum. Chem. Soc. Rev. 2017, 46, 5536-5550. [CrossRef] [PubMed]

3. Qin, C.-G.; Lu, C.-X.; Ouyang, G.-W.; Qin, K.; Zhang, F.; Shi, H.-T.; Wang, X.-H. Progress of Azobenzene-based Photoswitchable Molecular Probes and Sensory Chips for Chemical and Biological Analysis. Chin. J. Anal. Chem. 2015, 43, 433-443. [CrossRef]

4. Harrisa, J.D.; Morana, M.J.; Aprahamiana, I. New molecular switch architectures. Proc. Natl. Acad. Sci. USA 2018, 115, 9414-9422. [CrossRef] [PubMed] 
5. Whalley, A.C.; Steigerwald, M.L.; Guo, X.; Nuckolls, C. Reversible Switching in Molecular Electronic Devices. J. Am. Chem. Soc. 2007, 129, 12590-12591. [CrossRef]

6. Hüll, K.; Morstein, J.; Trauner, D. In Vivo Photopharmacology. Chem. Rev. 2018, 118, 10710-10747. [CrossRef]

7. Jia, S.; Fong, W.-K.; Graham, B.; Boyd, B.J. Photoswitchable Molecules in Long-Wavelength Light-Responsive Drug Delivery: From Molecular Design to Applications. Chem. Mater. 2018, 30, 2873-2887. [CrossRef]

8. Tochitsky, I.; Kienzler, M.A.; Isacoff, E.; Kramer, R.H. Restoring Vision to the Blind with Chemical Photoswitches. Chem. Rev. 2018, 118, 10748-10773. [CrossRef]

9. Micciarelli, M.; Altucci, C.; Della Ventura, B.; Velotta, R.; Tosa, V.; Gònzalez Pérez, A.B.; Pérez Rodrìguez, M.; de Lera, Á.R.; Bende, A. Low-lying excited-states of 5-benzyluracil. Phys. Chem. Chem. Phys. 2013, 15, 7161-7173. [CrossRef]

10. Micciarelli, M.; Valadan, M.; Della Ventura, B.; Di Fabio, F.; De Napoli, L.; Bonella, S.; Röthlisberger, U.; Tavernelli, I.; Altucci, C.; Velotta, R. Photophysics and Photochemistry of a DNA-Protein Cross-Linking Model: A Synergistic Approach Combining Experiments and Theory. J. Phys. Chem. B. 2014, 118, 4983-4992. [CrossRef]

11. Micciarelli, M.; Curchod, B.F.E.; Bonella, S.; Altucci, C.; Valadan, M.; Röthlisberger, U.; Tavernelli, I. Characterization of the Photochemical Properties of 5-Benzyluracil via Time-Dependent Density Functional Theory. J. Phys. Chem. A. 2017, 121, 3909-3917. [CrossRef]

12. Valadan, M.; Pomarico, E.; Della Ventura, B.; Gesuele, F.; Velotta, R.; Amoresano, A.; Pinto, G.; Chergui, M.; Improta, R.; Altucci, C. A multi-scale time-resolved study of photoactivated dynamics in 5-benzyl uracil, a model for DNA/protein interactions. Phys. Chem. Chem. Phys. 2019, 21, 26301-26310. [CrossRef]

13. Dhammika Bandarab, H.M.; Burdette, S.C. Photoisomerization in different classes of azobenzene. Chem. Soc. Rev. 2012, 41, 1809-1825.

14. Zhu, M.; Zhou, H. Azobenzene-based small molecular photoswitches for protein modulation. Org. Biomol. Chem. 2018, 16, 8434-8445. [CrossRef]

15. Merino, E.; Ribagorda, M. Control over molecular motion using the cis-trans photoisomerization of the azo group. Beilstein J. Org. Chem. 2012, 8, 1071-1090. [CrossRef]

16. Ankenbruck, N.; Courtney, T.; Naro, Y.; Deiters, A. Optochemical control of biological processes in cells and animals. Angew. Chem. Int. Ed. 2018, 57, 2768-2798. [CrossRef]

17. Garcia-Amorós, J.; Castro, M.C.R.; Coelho, P.; Raposo, M.M.M.; Velasco, D. New heterocyclic systems to afford microsecond green-light isomerisable azo dyes and their use as fast molecular photochromic switches. Chem. Comm. 2013, 49, 11427-11429. [CrossRef]

18. Yin, T.T.; Zhao, Z.X.; Zhang, H.X. A theoretical study on the thermal cis-trans isomerization of azoheteroarene photoswitches. New J. Chem. 2017, 41, 1659-1669. [CrossRef]

19. Calbo, J.; Weston, C.E.; White, A.J.P.; Rzepa, H.S.; Contreras-García, J.; Fuchter, M.J. Tuning Azoheteroarene Photoswitch Performance through Heteroaryl Design. J. Am. Chem. Soc. 2017, 139, 1261-1274. [CrossRef]

20. Imperatore, C.; Scuotto, M.; Valadan, M.; Rivieccio, E.; Saide, A.; Russo, A.; Altucci, C.; Menna, M.; Ramunno, A.; Mayol, L.; et al. Photo-control of cancer cell growth by benzodiazo N-substituted pyrrole derivatives. J. Photochem. Photobiol. A Chem. 2019, 377, 109-118. [CrossRef]

21. Alfarouk, K.O.; Muddathir, K.A.; Shayoub, M.E. Tumor Acidity as Evolutionary Spite. Cancers 2011, 3, 408-414. [CrossRef] [PubMed]

22. Swietach, P.; Vaughan-Jones, R.D.; Harris, A.L.; Hulikova, A. The chemistry, physiology and pathology of pH in cancer. Phil. Trans. R. Soc. B. 2014, 369. [CrossRef] [PubMed]

23. White, K.A.; Grillo-Hill, B.K.; Barber, D.L. Cancer cell behaviors mediated by dysregulated pH dynamics at a glance. J. Cell Sci. 2017, 130, 663-669. [CrossRef] [PubMed]

24. Anderson, M.; Moshnikova, A.; Engelman, D.M.; Reshetnyak, Y.K.; Andreev, O.A. Probe for the measurement of cell surface $\mathrm{pH}$ in vivo and ex vivo. Proc. Natl. Acad. Sci. USA 2016, 113, 8177-8181. [CrossRef] [PubMed]

25. Emond, M.; Le Saux, T.; Maurin, S.; Baudin, J.-B.; Plasson, R.; Jullien, L. 2-Hydroxyazobenzenes to Tailor pH Pulses and Oscillations with Light. Chem. Eur. J. 2010, 16, 8822-8831. [CrossRef] [PubMed]

26. Samanta, S.; Babalhavaeji, A.; Dong, M.-X.; Woolley, G.A. Photoswitching of ortho-Substituted Azonium Ions by Red Light in Whole Blood. Angew. Chem. Int. Ed. 2013, 52, 14127-14130. [CrossRef]

27. Dunn, N.J.; Humphries, W.H., 4th; Offenbacher, A.R.; King, T.L.; Gray, J.A. pH-Dependent cis $\mathrm{f}$ trans Isomerization Rates for Azobenzene Dyes in Aqueous Solution. J. Phys. Chem. A 2009, 113, 13144-13151. [CrossRef] 
28. Dong, M.; Babalhavaeji, A.; Hansen, M.J.; Kalmanb, L.; Woolley, G.A. Red, far-red, and near infrared photoswitches based on azonium ions. Chem. Commun. 2015, 51, 12981-12984. [CrossRef]

29. Emond, M.; Sun, J.; Gregoire, J.; Maurin, S.; Tribet, C.; Jullien, L. Photoinduced pH drops in water. Phys. Chem. Chem. Phys. 2011, 13, 6493-6499. [CrossRef]

30. Budac, D.; Want, P. Photodecarboxylation: Mechanism and synthetic utility. J. Photochem. Photobiol. A Chem. 1992, 67, 135-166. [CrossRef]

31. Blaise, E.; Kummerle, A.E.; Hammoud, H.; de Araujo-Junior, J.X.; Bihel, F.; Bourguignon, J.-J.; Schmitt, M. Access to 4-Alkylaminopyridazine Derivatives via Nitrogen-Assisted Regioselective Pd-Catalyzed Reactions. J. Org. Chem. 2014, 79, 10311-10322. [CrossRef] [PubMed]

32. Fehler, S.K.; Pratsch, G.; Heinrich, M.R. The Trapping of Phenyldiazenes in Cycloaddition Reactions. Angew. Chem. Int. Ed. 2014, 53, 11361-11365. [CrossRef] [PubMed]

33. Jurberg, I.D.; Davies, H.M.L. Blue light-promoted photolysis of aryldiazoacetates. Chem. Sci. 2018, 9, 5112-5118. [CrossRef] [PubMed]

34. Menna, M.; Aiello, A.; D’Aniello, F.; Fattorusso, E.; Imperatore, C.; Luciano, P.; Vitalone, R. Further investigation of the mediterranean sponge Axinella polypoides: Isolation of a new cyclonucleoside and a new betaine. Mar. Drugs 2012, 10, 2509-2518. [CrossRef]

35. Imperatore, C.; D'Aniello, F.; Aiello, A.; Fiorucci, S.; D'Amore, C.; Sepe, V.; Menna, M. Phallusiasterols A and B: Two new sulfated sterols from the mediterranean tunicate Phallusia fumigata and their effects as modulators of the PXR receptor. Mar. Drugs 2014, 12, 2066-2078. [CrossRef]

36. Casertano, M.; Imperatore, C.; Luciano, P.; Aiello, A.; Menna, M.; Putra, M.Y.; Gimmelli, R.; Ruberti, G. Chemical Investigation of the Indonesian Tunicate Polycarpa aurata and Evaluation of the Effects Against Schistosoma mansoni of the Novel Alkaloids Polyaurines A and B. Mar. Drugs 2019, 17, 278. [CrossRef]

37. Gourlay, B.S.; Molesworth, P.P.; Ryan, J.H.; Smith, J.A. A new and high yielding synthesis of unstable pyrroles via a modified Clauson-Kaas reaction. Tetrahedron Lett. 2006, 47, 799-801. [CrossRef]

38. Fletcher, R. Unconstrained optimization. In Practical Methods of Optimization, 1st ed.; John Wiley \& Sons Ltd.: New York, NY, USA, 1980; Volume 1, pp. 1-128. ISBN 978-0471277118.

39. Ewig, C.S.; Berry, R.; Dinur, U.; Hill, J.R.; Hwang, M.J.; Li, H.; Liang, C.; Maple, J.; Peng, Z.; Stockfisch, T.P.; et al. Derivation of class II force fields. VIII. Derivation of a general quantum mechanical force field for organic compounds. J. Comput. Chem. 2001, 22, 1782-1800. [CrossRef]

40. Frisch, M.J.; Trucks, G.W.; Schlegel, H.B.; Scuseria, G.E.; Robb, M.A.; Cheeseman, J.R.; Scalmani, G.; Barone, V.; Mennucci, B.; Petersson, G.A.; et al. Gaussian 09; Revision A.1; Gaussian Inc.: Wallingford, CT, USA, 2009.

41. Becke, D. Density-functional thermochemistry. III. The role of exact exchange. J. Chem. Phys. 1993, 98, 5648-5652. [CrossRef]

42. Lee, C.; Yang, W.; Parr, R.G. Development of the Colle-Salvetti correlation-energy formula into a functional of the electron density. Phys. Rev. B Condens. Matter Mater. Phys. 1988, 37, 785-789. [CrossRef]

43. Cossi, M.; Rega, N.; Scalmani, G.; Barone, V. Energies, structures, and electronic properties of molecules in solution with the C-PCM solvation model. J. Comp. Chem. 2003, 24, 669-681. [CrossRef] [PubMed]

44. Reed, E.; Weinstock, R.B.; Weinhold, F. Natural Population Analysis. J. Chem. Phys. 1985, 83, 735-746. [CrossRef]

(C) 2020 by the authors. Licensee MDPI, Basel, Switzerland. This article is an open access article distributed under the terms and conditions of the Creative Commons Attribution (CC BY) license (http://creativecommons.org/licenses/by/4.0/). 